\title{
Field intercomparison of four methane gas analyzers suitable for eddy covariance flux measurements
}

\author{
O. Peltola ${ }^{1}$, I. Mammarella ${ }^{1}$, S. Haapanala ${ }^{1}$, G. Burba ${ }^{2}$, and T. Vesala ${ }^{1}$ \\ ${ }^{1}$ Department of Physics, University of Helsinki, P.O. Box 48, Helsinki 00014, Finland \\ ${ }^{2}$ LI-COR Biosciences, 4421 Superior Street, Lincoln, NE 68504, USA \\ Correspondence to: O. Peltola (olli.peltola@helsinki.fi) \\ Received: 22 August 2012 - Published in Biogeosciences Discuss.: 12 December 2012 \\ Revised: 8 March 2013 - Accepted: 9 May 2013 - Published: 11 June 2013
}

\begin{abstract}
.
Performances of four methane gas analyzers suitable for eddy covariance measurements are assessed. The assessment and comparison was performed by analyzing eddy covariance data obtained during summer 2010 (1 April to 26 October) at a pristine fen, Siikaneva, Southern Finland. High methane fluxes with pronounced seasonality have been measured at this fen. The four participating methane gas analyzers are commercially available closedpath units TGA-100A (Campbell Scientific Inc., USA), RMT-200 (Los Gatos Research, USA), G1301-f (Picarro Inc., USA) and an early prototype open-path unit Prototype7700 (LI-COR Biosciences, USA).

The RMT-200 functioned most reliably throughout the measurement campaign, during low and high flux periods. Methane fluxes from RMT-200 and G1301-f had the smallest random errors and the fluxes agree remarkably well throughout the measurement campaign. Cospectra and power spectra calculated from RMT-200 and G1301-f data agree well with corresponding temperature spectra during a high flux period. None of the gas analyzers showed statistically significant diurnal variation for methane flux. Prototype-7700 functioned only for a short period of time, over one month, in the beginning of the measurement campaign during low flux period, and thus, its overall accuracy and season-long performance were not assessed. The open-path gas analyzer is a practical choice for measurement sites in remote locations due to its low power demand, whereas for G1301-f methane measurements interference from water vapor is straightforward to correct since the instrument measures both gases simultaneously. In any case, if only the performance in this intercomparison is considered, RMT-200 performed the best and
\end{abstract}

is the recommended choice if a new fast response methane gas analyzer is needed.

\section{Introduction}

Prior to 1990s, eddy covariance (EC) measurements of methane flux were impossible due to lack of "fast" gas analyzers needed in order to capture turbulent flux transport at all relevant frequencies, or eddy sizes. However, after the development of fast instruments based on the laser absorption spectroscopy (LAS), studies reporting ecosystem scale EC methane flux measurements started to occur more frequently (e.g., Verma et al., 1992; Suyker et al., 1996; Rinne et al., 2007). The early studies employed instruments which needed continuous maintenance, and whose sampling resolution was not very high. Furthermore, estimating long-term methane balance was quite expensive and a laborious task due to substantial need of continuous upkeep. The lasers needed to be cooled to cryogenic temperature in order to function properly, and such cooling was usually done with liquid nitrogen which further increased the maintenance requirements.

Recent advancements in the development of LAS gas analyzers have made sensitive and robust instruments commercially available, and accordingly, the number of gas analyzers applicable for EC measurements increased. The new instruments function at room temperature which drastically decreases maintenance needs. The growing use of LAS gas analyzers for eddy covariance methane flux measurements calls for comparison between the instruments. Tuzson et al. (2010) assessed and intercompared performance of two rather new gas analyzers at a grassland site with an artificially created 
methane flux. Their gas release experiment lasted the total of eleven days. While they were able to assess if flux magnitude was measured correctly, they were not able to determine instruments' long-term performance in field conditions, which is a key issue for continuous greenhouse gas monitoring.

The objective of this study is to compare and assess the performance of four methane gas analyzers and corresponding methane fluxes. This is done by analyzing methane flux data measured during April-October 2010 at Siikaneva fen, Southern Finland. Four methane gas analyzers and one sonic anemometer were used to acquire four methane flux estimates. Season-long performance is assessed by comparing data coverage and estimates for methane budgets, while short-term performance is assessed by analyzing random and systematic errors in the methane flux, and also, by examining spectral characteristics of measured turbulent fluctuations. One of the participating analyzers, TGA-100A (Campbell Scientific Inc., USA) (e.g., Billesbach et al., 1998), is an older closed-path model, and is based on the same principle as the gas analyzers used in the early studies in the 1990s. The two other closed-path models, RMT-200 (Los Gatos Research, USA) (e.g., Baer et al., 2002; Hendriks et al., 2008; Eugster and Pluess, 2010; Tuzson et al., 2010), G1301-f (Picarro Inc., USA), and an early open-path prototype, Prototype-7700 (LI-COR Biosciences, USA) (e.g., McDermitt et al., 2010; Dengel et al., 2011; Detto et al., 2011), are new state-of-the-art instruments. The three closed-path units operated with occasional breaks throughout the measurement campaign, whereas Prototype-7700 malfunctioned permanently at 11 June due to water leakage which damaged internal electronics of the instrument.

\section{Materials and methods}

\subsection{Site description}

The gas analyzer intercomparison was carried out between 1 April and 26 October 2010, in Siikaneva fen, Southern Finland $\left(61^{\circ} 49.961^{\prime} \mathrm{N}, 24^{\circ} 11.567^{\prime} \mathrm{E}, 160 \mathrm{~m}\right.$ a.s.l). Siikaneva is a nutrient-poor oligotrophic open fen. Distance from the study site to the tree line is in north and south directions about $200 \mathrm{~m}$, and several hundred meters in east and west directions (Fig. 1). Surrounding forest consists mainly of Scots pines. Peat depth varies from 2 to $4 \mathrm{~m}$, increasing toward the center of the site. The surface topography is relatively flat with no pronounced slope (Aurela et al., 2007). Vegetation height is low, approximately $10-30 \mathrm{~cm}$. Due to the topography and relatively large homogeneous fetch, this location is well-suited for eddy covariance flux measurements. The vegetation at the site consists mainly of sedges (Eriophorum vaginatum, Carex rostrata, C. limosa) and Sphagnum-species, namely $S$. balticum, S. majus and S. papillosum. More about vegetation and carbon gas exchange in the study site can be found in Riutta et al. (2007).

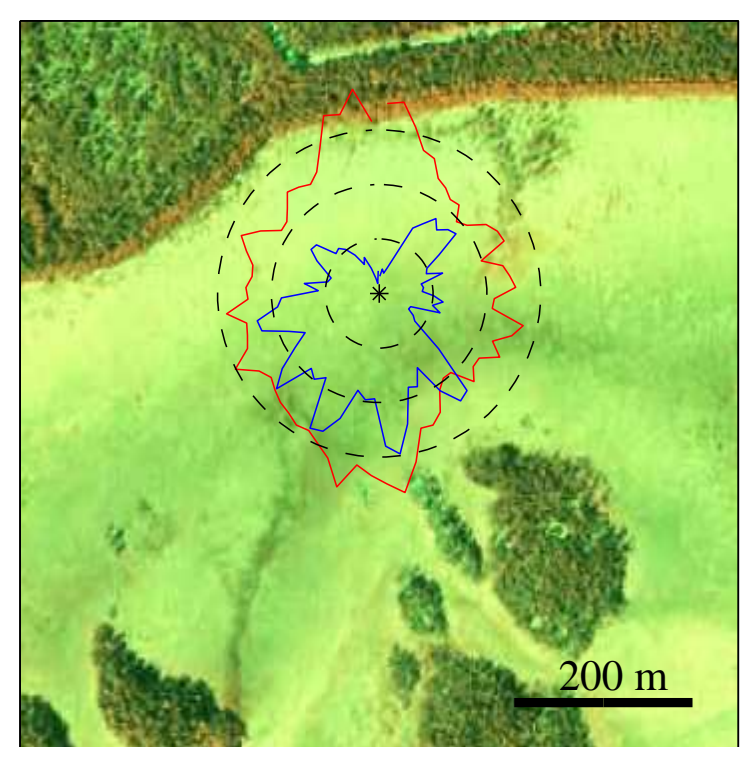

Fig. 1. Aerial photograph of the measurement site. Light green area shows area governed by the fen and the darker green area represents the surrounding forest. Star marks location of the measurement tower, red and blue lines show average methane flux and amount of obtained methane flux data as a function of wind direction, respectively. Methane flux is in units $\mathrm{mg} \mathrm{m}^{-2} \mathrm{~h}^{-1}$ and dashed lines show where methane flux equals 1,2 and $3 \mathrm{mg} \mathrm{m}^{-2} \mathrm{~h}^{-1}$ and amount of data equals 60, 120 and 180 points. Data obtained from RMT-200 was used in this plot.

Air temperature during the measurement campaign was on average $11.5^{\circ} \mathrm{C}$, a $2.2^{\circ} \mathrm{C}$ warmer than 30 -yr average, recorded at a nearby meteorological station (Drebs et al., 2002). July was the hottest month with mean air temperature of $20.7^{\circ} \mathrm{C}$. Peat was not frozen during the whole time period. Accumulated precipitation during the measurement period was $372 \mathrm{~mm}$, while Drebs et al. (2002) reported a value of $429 \mathrm{~mm}$ for $30 \mathrm{yr}$ average.

\subsection{Measurement system}

Micrometeorological measurement systems observing trace gas fluxes usually consist of sonic anemometer and at least one gas analyzer. At the Siikaneva site, three-axis sonic anemometer (USA-1, METEK, Germany) was used to measure three wind components and air temperature. $\mathrm{CO}_{2}$ and $\mathrm{H}_{2} \mathrm{O}$ concentrations were measured with a closedpath gas analyzer (LI-7000, LI-COR Biosciences, Lincoln, NE, USA). Sonic anemometer was situated at $2.75 \mathrm{~m}$ height above soil surface, and the sampling inlet for LI-7000 was situated $25 \mathrm{~cm}$ below the sonic anemometer. The sampling tube consisted of two parts: $16 \mathrm{~m}$ long tube with $10 \mathrm{~mm}$ inner diameter followed by a $0.8 \mathrm{~m}$ long tube with $4 \mathrm{~mm}$ inner diameter. The longer part was used to sample air also to some of the methane gas analyzers. Both of the tubes were made of Teflon. The whole sampling line was heated in order to avoid 
Table 1. Characteristics of the four methane gas analyzers and their respective setups.

\begin{tabular}{|c|c|c|c|c|}
\hline & Prototype-7700 & G1301-f & TGA-100A & RMT-200 \\
\hline Analyzer type & $\begin{array}{r}\text { open-path analyzer } \\
\text { enhanced with WMS }\end{array}$ & WS-CRDS & TDLAS & off-axis ICOS \\
\hline Open/closed path & open & closed & closed & closed \\
\hline Measured species & $\mathrm{CH}_{4}$ & $\mathrm{CH}_{4}, \mathrm{H}_{2} \mathrm{O}$ & $\mathrm{CH}_{4}$ & $\mathrm{CH}_{4}$ \\
\hline $\begin{array}{l}\text { Sampling height } \\
\text { above the soil }\end{array}$ & $2.3 \mathrm{~m}$ & $2.5 \mathrm{~m}$ & $2.5 \mathrm{~m}$ & $2.5 \mathrm{~m}$ \\
\hline $\begin{array}{l}\text { Sampling height } \\
\text { above significant structures }\end{array}$ & $1.1 \mathrm{~m}$ & $2.5 \mathrm{~m}$ & $2.5 \mathrm{~m}$ & $2.5 \mathrm{~m}$ \\
\hline Horizontal sensor separation & $10 \mathrm{~cm}$ & $5 \mathrm{~cm}$ & $5 \mathrm{~cm}$ & $5 \mathrm{~cm}$ \\
\hline Vertical sensor separation & $45 \mathrm{~cm}$ & $25 \mathrm{~cm}$ & $30 \mathrm{~cm}$ & $25 \mathrm{~cm}$ \\
\hline Length of sampling line & - & $16.8 \mathrm{~m}$ & $13 \mathrm{~m}$ & $15 \mathrm{~m}$ \\
\hline Flow rate & wind speed & 10 LPM & 14 LPM & 12 LPM \\
\hline Sample cell volume & open & $33 \mathrm{~cm}^{3}$ & $480 \mathrm{~cm}^{3}$ & $408 \mathrm{~cm}^{3}$ \\
\hline Sample cell pressure & ambient pressure & $187 \mathrm{hPa}$ & $60 \mathrm{hPa}$ & $189 \mathrm{hPa}$ \\
\hline Connected to dryer & No & No & Yes & No \\
\hline \multirow[t]{2}{*}{ System power demand } & low & high & high & high \\
\hline & (solar- and wind-powered) & (grid powered) & (grid powered) & (grid powered) \\
\hline Need of maintenance & low & low & high & low \\
\hline
\end{tabular}

condensation of water vapor on the tube walls. Flow rate in the main intake tube was approximately 24 LPM. Standard membrane pump (KNF N035.1.2AN, KNF Neuberger GmbH, Freiburg, Germany)) and Busch SAMOS SB0080D blower (Ateliers Busch S.A., Chevenez, Switzerland) were accompanying LI-7000. Horizontal spatial separation between the sampling tube inlet and sonic probe was approximately $5 \mathrm{~cm}$. Four methane gas analyzers were also installed at the same site, and their characteristics are shown in Table 1 and explained in more detail below. Calibration of all the four the methane analyzers was checked in a lab before field deployment with gases close to ambient $\mathrm{CH}_{4}$ concentration. All the analyzers showed similar values for $\mathrm{CH}_{4}$ concentration during the lab test and therefore no additional calibration was done. All measurements related to eddy covariance were recorded at the rate of $10 \mathrm{~Hz}$. Supporting meteorological and soil parameters were measured in the vicinity of eddy covariance measurement system.

\subsubsection{LI-COR Prototype-7700}

Prototype-7700 is an early pre-production prototype of the open-path methane gas analyzer (LI-COR Biosciences, USA). Open-path design does not utilize an intake tube or pump to pull the sampled air into the closed measurement cell; rather the measurements are done in situ, in an open cell, through which air flows freely moved by the wind. The analyzer employs a $0.47 \mathrm{~m}$ long open Herriott cell, with $30 \mathrm{~m}$ of optical path length. The analyzer was placed under the sonic anemometer resulting in approximately $10 \mathrm{~cm}$ horizontal and $45 \mathrm{~cm}$ vertical sensor separation distances. The measurement height was $2.3 \mathrm{~m}$ above soil surface and $1.1 \mathrm{~m}$ above surface of a wooded structure. Tunable diode laser is utilized to cre- ate laser beams in the near-infrared region. Methane concentration is measured by using wavelength modulation spectroscopy (WMS) in order to increase measurement accuracy and reduce the effects of mirror contamination. The concentration is determined by scanning over absorption line near $1.65 \mu \mathrm{m}$. This scanning is executed at $1 \mathrm{kHz}$ frequency (McDermitt et al., 2010).

\subsubsection{Picarro G1301-f}

G1301-f (Picarro Inc., USA) is based on wavelength-scanned cavity ring down spectroscopy (WS-CRDS), which is a modified version of a more traditional CRDS approach (O'Keefe and Deacon, 1988). Picarro G1301-f is a closed-path gas analyzer, with sampled air pulled into the cell via the $16 \mathrm{~m}$ long intake tube (same one as for LI-7000). The $0.8 \mathrm{~m}$ long tube was attached between the main sampling line and the gas analyzer, and thus, the total length of the sampling line was $16.8 \mathrm{~m}$. The tube inlet with a filter was situated $25 \mathrm{~cm}$ below the sonic anemometer, at the measurement height $2.5 \mathrm{~m}$ above the soil surface. Vacuubrand MD4NT vacuum pump (Vacuubrand GmbH, Wertheim, Germany) and Busch SAMOS SB0080D blower (Ateliers Busch S.A., Chevenez, Switzerland) were used in sucking the air through the sampling line and the analyzer. The analyzer was measuring water vapor and methane concentrations. Due to clogging of an internal filter, it was replaced 26 August with an external Pall Acro 50 filter (PTFE membrane $1 \mu \mathrm{m}$, Pall Acro 50).

\subsubsection{Los Gatos RMT-200}

RMT-200 is also a closed-path methane gas analyzer (Los Gatos Research, USA). It is based on the off-axis integrated 
cavity output spectroscopy (OA-ICOS), which differs from regular ICOS by the fact that the laser is placed at an angle to the axis of the cavity. A $15 \mathrm{~m}$ long Teflon sampling tube $8 \mathrm{~mm}$ in diameter was utilized to sample air to the gas analyzer. Vertical and horizontal separation between sonic probe and inlet of the tube was $25 \mathrm{~cm}$ and $5 \mathrm{~cm}$, respectively. The measurement height was $2.5 \mathrm{~m}$ above soil surface. The tube was not heated but it was situated inside a protective cover next to the heated tube used to sample air for LI-7000 and G1301-f. Edwards XDS35i pump (Edwards, Crawley, UK) was used in sampling the air. AcroPak filter (PTFE membrane $0.2 \mu \mathrm{m}$, Pall AcroPak 300) was attached to the inlet line, just before the analyzer.

\subsubsection{Campbell TGA-100A}

Campbell TGA-100A closed-path gas analyzer (Campbell Scientific Inc., USA) is based on TDLAS measurement technique applied with tunable lead-salt diode laser. This instrument has been widely used in eddy covariance methane flux measurement studies (e.g., Rinne et al., 2007), and is used in this study as a reference for the three new instruments. The laser was cooled using liquid nitrogen. Air was sampled with $13 \mathrm{~m}$ long Teflon tube with $4 \mathrm{~mm}$ inner diameter. Air was sucked through a filter (polypropylene/polyethylene membrane $10 \mu \mathrm{m}$, Pall 60344). Flow rate in the tube was 14 LPM provided by Edwards XDS35i pump (Edwards, Crawley, UK). The inlet was situated at $2.45 \mathrm{~m}$ height above soil surface resulting in $30 \mathrm{~cm}$ vertical sensor separation between sonic probe and the inlet. Tube was not heated but the air was dried with a diffusion drier (Nafion PD-1000, Perma pure Inc., USA) located after the inlet. Dew point temperature remained at about -15 to $-30^{\circ} \mathrm{C}$. Due to this, WPL terms or spectroscopic corrections were not needed.

\subsection{Eddy covariance method}

Eddy covariance method was used in measuring the vertical turbulent fluxes of trace gases, sensible and latent heat (Aubinet et al., 2000):

$$
\begin{aligned}
H & =\overline{\rho_{\mathrm{a}}} c_{p} \overline{w^{\prime} T^{\prime}} \\
\mathrm{LE} & =\mathrm{L} \overline{\rho_{\mathrm{a}}} \overline{w^{\prime} \chi_{\mathrm{v}}{ }^{\prime}} \\
F_{c} & =\overline{\rho_{\mathrm{a}}} \overline{w^{\prime} \chi_{c}}
\end{aligned}
$$

where $H$ and LE are sensible heat and latent heat fluxes, respectively, and $F_{c}$ is turbulent flux of arbitrary scalar $c$. L is defined as latent heat of vaporization of water, $\chi_{\mathrm{v}}$ water vapor mass mixing ratio $\left(\mathrm{kg}_{\text {water }} / \mathrm{kg}_{\text {dry air }}\right), T$ is temperature, $\overline{\rho_{\mathrm{a}}}$ is mean air mass density, $c_{p}$ is the specific heat at constant pressure and $\chi_{c}$ is mass mixing ratio of scalar $c\left(\mathrm{~kg}_{\mathrm{gas}} / \mathrm{kg}_{\text {dry air }}\right)$. $w$ is the vertical component of 3-D wind vector. Equation (3) can describe flux of any scalar, for instance methane, carbon dioxide, ozone, etc. The fluxes are defined to be positive when directed upwards.
Data was processed with post-processing software EddyUH (http://www.atm.helsinki.fi/Eddy_Covariance/). Measurements were sampled at $10 \mathrm{~Hz}$ frequency, and 30-min averaging time was used in calculating the covariances. For the most part, data processing followed the methodology described by Aubinet et al. (2000). First the high frequency eddy covariance data were despiked by comparing two adjacent measurements. If there were over $0.5 \mathrm{ppm}$ difference between two adjacent methane concentration measurements, the following point was replaced with the same value as in the previous point. Second, the coordinate rotation was applied: wind components $u, v$ and $w$ were rotated so that $u$ was directed toward mean horizontal wind speed and second rotation set the mean vertical wind speed $\bar{w}$ to zero (Kaimal and Finnigan, 1994). Third, the mean values were removed from the time series using block-averaging method. Fourth, time lag between the concentration and wind measurements induced by the sampling lines was corrected by maximizing the covariance. Fifth, spectral corrections were applied (Sect. 2.3.1). Then, humidity effect on temperature flux $\overline{w^{\prime} T^{\prime}}$ was accounted for after Schotanus et al. (1983). As a final step, Webb-Pearman-Leuning (WPL) terms and spectroscopic corrections were applied according to the method presented in Sect. 2.3.2.

Turbulent cospectra and power spectra were obtained by applying Fast Fourier Transform (FFT) to linearly detrended, Hamming-windowed, raw high-frequency eddy covariance data. Cospectra were used to determine frequency response of the measurement systems. Both cospectra and power spectra are analyzed in Sect. 3.2.

\subsubsection{Spectral corrections}

Attenuation of low frequency variation was corrected with transfer function $\left(\mathrm{TF}_{\mathrm{LF}}\right)$ after Rannik and Vesala (1999), while attenuation of high frequency variations was corrected with transfer function after Horst (1997):

$\mathrm{TF}_{\mathrm{HF}}=\frac{1}{1+(2 \pi f \tau)^{2}}$

where $f$ is natural frequency and $\tau$ is measurement systemspecific coefficient, called response time. $\tau$ is related to the cut-off frequency $f_{c}$ via $\tau=1 /\left(2 \pi f_{c}\right)$. Cut-off frequency corresponds to that frequency where the transfer function equals $2^{-1 / 2}$, meaning that the flux has been attenuated to approximately 0.7 of the real value at this frequency. $\tau$ was determined for each gas analyzer experimentally by assuming scalar similarity and comparing normalized temperature and methane cospectra. Magnitude of signal attenuation can be estimated with correction factor CF (Aubinet et al., 2000): 


$$
\mathrm{CF}=\frac{\int_{0}^{\infty} S_{w T}^{\text {model }}(f) \mathrm{d} f}{\int_{0}^{\infty} \operatorname{TF}_{\mathrm{HF}}(f) \operatorname{TF}_{\mathrm{LF}}(f) S_{w T}^{\text {model }}(f) \mathrm{d} f}
$$

where $S_{w T}^{\text {model }}$ is the scalar model cospectrum, estimated by fitting a curve to the measured temperature cospectrum similarly to Mammarella et al. (2010). Now by multiplying measured flux with correction factor $\mathrm{CF}$, the fluxes can be corrected for signal attenuation.

\subsubsection{Effect of water vapor and temperature fluctuations on gas concentration measurements}

Pressure, temperature and water vapor affect the shape and width of the absorption lines used to deduce gas concentration, and thus, gas concentration measured with a laser may not be equal to the real gas concentration. The effect of this on the fluxes can be corrected with the so-called spectroscopic correction. These effects are absorption line-specific features and they also depend on the spectroscopic approach used to measure the gas. Thus, gas analyzers using different absorption lines will have different spectroscopic effects on the measured fluxes. This has to be accounted for when the magnitude of apparent fluxes is estimated and corrected.

Gas concentration measurements are also affected by air density fluctuations (Webb et al., 1980; Massman and Tuovinen, 2006) and these effects can be corrected by adding the Webb-Pearman-Leuning (WPL) density terms to the measured flux. In these, the effect of atmospheric pressure fluctuations on measured density is assumed negligible, however during recent years the validity of this assumption has been questioned (Lee and Massman, 2011; Nakai et al., 2011; Zhang et al., 2011; Burba et al., 2012). Results from these studies are inconsistent with each other, but generally concur that the small effects of the pressure fluctuations are not negligible in all cases. Significance of fluctuations in atmospheric pressure was tested with the method proposed by Lee and Massman (2011) and parameterization adopted from McBean and Elliott (1975). For the study site, the pressure fluctuations had on average two orders of magnitude smaller effect on gas concentration measurements than water vapor fluctuations. Therefore, in this study atmospheric pressure is assumed constant.

The Prototype-7700 flux data was corrected for density fluctuations and spectroscopic effects at the same time (Burba et al., 2009; McDermitt et al., 2010):

$$
F_{c}^{\text {corr }}=A\left\{\overline{w^{\prime} \rho_{\mathrm{cm}}{ }^{\prime}}+B \mu \frac{\overline{\rho_{\mathrm{cm}}}}{\overline{\rho_{\mathrm{a}}} \mathrm{L}} \mathrm{LE}+C \frac{(1+\mu \sigma) \overline{\rho_{\mathrm{cm}}}}{\overline{\rho_{\mathrm{a}}} c_{p} \bar{T}} H\right\}
$$

where

$A=\bar{\kappa}$

$B=1+\left(1-1.46 \overline{\xi_{\mathrm{v}}}\right) \alpha_{\mathrm{v}} \overline{P_{\mathrm{e}}} \frac{\kappa_{P_{\mathrm{e}}}}{\bar{\kappa}}$

$C=1+\left(1-\overline{\xi_{\mathrm{v}}}\right) \bar{T} \frac{\kappa_{T}}{\bar{\kappa}}+\overline{\xi_{\mathrm{v}}}(B-1)$

and $\rho_{\mathrm{cm}}$, and $\rho_{\mathrm{a}}$ are uncorrected methane and air mass density, respectively, $\kappa$ is a dimensionless correction factor which is a function of temperature and equivalent pressure $P_{\mathrm{e}}$ (Burch et al., 1962), $\kappa_{P_{\mathrm{e}}}$ and $\kappa_{T}$ are the partial derivatives of $\kappa$ with respect to pressure and temperature, computed at $T=\bar{T}$ and $P_{\mathrm{e}}=\overline{P_{\mathrm{e}}}$, respectively. $\mu$ is molar mass of air divided with molar mass of water, $\sigma$ is mean water vapor density divided with mean air density and $\xi_{\mathrm{v}}$ is mole fraction of water vapor $\left(\mathrm{mol}_{\mathrm{water}} / \mathrm{mol}_{\text {air }}\right)$. With this equation spectroscopic effects can be corrected simultaneously with density fluctuation induced errors, i.e., WPL terms.

In a closed-path gas analyzer temperature fluctuations in the sample gas are damped while the gas is transported in the long tube (Leuning and Moncrieff, 1990; Rannik et al., 1997). Thus, air sample temperature is effectively constant in the sampling cell, meaning that the spectroscopic effects and density fluctuation caused by temperature fluctuations may be neglected.

For closed-path gas analyzer RMT-200 the spectroscopic effects were corrected by adding water vapor flux multiplied with certain factor $b_{\mathrm{ct}}$ to the measured trace gas flux (Neftel et al., 2010; Tuzson et al., 2010):

$F_{c}^{\mathrm{SP}}=F_{c}^{\text {meas }}+b_{\mathrm{ct}} \frac{M_{c}}{M_{\mathrm{v}} \mathrm{L}} \mathrm{LE}$

where $F_{c}^{\text {meas }}$ is measured flux (Eq. 3), $F_{c}^{\mathrm{SP}}$ is flux corrected for the spectroscopic effects and $M_{c}$ and $M_{\mathrm{v}}$ are molar masses of scalar $c$ and water vapor, respectively. The instrument specific coefficient $b_{\mathrm{ct}}$ was adopted from Tuzson et al. (2010) with some modifications. Their $b_{\mathrm{ct}}$ incorporates both corrections (spectroscopic and WPL) in the same $b_{\mathrm{ct}}$ value, and they also state that the spectroscopic correction is approximately $16 \%$ of WPL $\mathrm{H}_{2} \mathrm{O}$-term, so in our study $b_{\text {ct }}$ was set to $3.965 \times 10^{-7}$ mol $_{\mathrm{CH}_{4}} \mathrm{~mol}_{\mathrm{H}_{2} \mathrm{O}}^{-1}$, which is $16 \%$ of the value that Tuzson et al. (2010) reported. This value also agrees with our lab results. Effect of density fluctuations were corrected using the traditional approach for closedpath gas analyzers (Eq. (6) with $A=B=1$ and $C=0$ ). $L E$ used to correct closed-path gas analyzer measurements should correspond to the conditions in the gas measurement cell (Ibrom et al., 2007), meaning that $L E$ should be calculated with $\mathrm{CH}_{4}$ time lag and it should be attenuated to the degree that the closed-path gas analyzer sampling line attenuates $\mathrm{H}_{2} \mathrm{O}$ fluctuations. In this study LI-7000 $\mathrm{H}_{2} \mathrm{O}$ measurements were used to correct RMT-200 $\mathrm{CH}_{4}$ flux data. However, RMT-200 and LI-7000 had different sampling lines with different flow rates and filters, and thus, LI-7000 measurements do not fully describe the circumstances in RMT200 measurement cell. Therefore, some residual error, on the 
order of $1-30 \%$ of the correction, is expected when using LI-7000 $\mathrm{H}_{2} \mathrm{O}$ to correct RMT-200 data.

For G1301-f the corrections were performed using the method and coefficients presented in Chen et al. (2010). They use second order polynomial function which describes the effect of $\mathrm{H}_{2} \mathrm{O}$ on methane concentration measurements. The correction is done point-by-point to the raw data using $\mathrm{H}_{2} \mathrm{O}$ measured by the instrument itself. After 26th of August the instrument was not any more measuring $\mathrm{H}_{2} \mathrm{O}$ and thus correction described in Chen et al. (2010) could not be used anymore. After this date only WPL correction could be done to the data and it was done using $\mathrm{H}_{2} \mathrm{O}$ measured with LI-7000. Closed-path gas analyzer TGA-100A was connected to dryer and therefore the $\mathrm{CH}_{4}$ measurements were free of any interference from $\mathrm{H}_{2} \mathrm{O}$ and these corrections were not needed.

\subsection{Random error estimation methods}

Errors in measurements can be systematic or random. Errors resulting in random uncertainties do not introduce any bias to the calculated flux; rather they decrease reliability of the measurement. Eddy covariance trace gas flux measurements have various sources for random uncertainties. They are related to atmospheric conditions, measurement and data analysis methods and measurement site characteristics (Businger, 1986; Kroon et al., 2010).

According to Kroon et al. (2010) the uncertainty of measured covariance $\overline{w^{\prime} \chi_{c}{ }^{\prime}}$ is dominated by the uncertainty that is related to one-point sampling of the flux. This is due to the fact that they assume that uncertainty due to measurement precision of vertical wind $w$ and mixing ratio $\chi_{c}$ are negligible. One-point uncertainty is linearly proportional to standard deviation of the measured covariance (Businger, 1986), and thus by comparing the standard deviations of covariances, it is possible to compare uncertainties in the four methane flux estimates. The standard deviations of the covariances were calculated according to method proposed by Finkelstein and Sims (2001):

$\sigma_{F}=\sqrt{\frac{1}{n_{\mathrm{s}}}\left[\sum_{p=-m}^{m} \hat{\gamma}_{c, c}(p) \hat{\gamma}_{w, w}(p)+\sum_{p=-m}^{m} \hat{\gamma}_{w, c}(p) \hat{\gamma}_{c, w}(p)\right]}$

where $n_{\mathrm{S}}$ is the total number of samples in a dataset, $m$ is a number samples that is sufficiently large in order to cover the integral timescale (e.g., Stull, 1988) and $\hat{\gamma}_{c, c}$ and $\hat{\gamma}_{c, w}$ are autocovariance and cross-covariance functions, respectively. In this study, $n_{\mathrm{S}}$ equals 18000 due to $10 \mathrm{~Hz}$ sampling frequency and $30 \mathrm{~min}$ averaging time, $m$ is equal to 200 , as suggested by Finkelstein and Sims (2001), and auto- and crosscovariance functions were calculated as

$$
\begin{aligned}
& \hat{\gamma}_{x, x}(p)=\hat{\gamma}_{x, x}(-p)=\frac{1}{n_{\mathrm{s}}} \sum_{t=1}^{n_{\mathrm{s}}-p}\left(x_{t}-\bar{x}\right)\left(x_{t+p}-\bar{x}\right) \\
& \hat{\gamma}_{x, y}(p)=\hat{\gamma}_{y, x}(-p)=\frac{1}{n_{\mathrm{s}}} \sum_{t=1}^{n_{\mathrm{s}}-p}\left(x_{t}-\bar{x}\right)\left(y_{t+p}-\bar{y}\right)
\end{aligned}
$$

This mathematically rigorous method provides estimates for the random uncertainty in flux measurements for every averaging period. Finkelstein and Sims (2001) argue that this method provides a better estimate for the standard deviation of the covariance than previously reported methods. This is due to the fact that it does not assume any kind of cospectral or spectral shapes for the turbulent transport; more like the method is based on direct statistical calculation of variance of covariance.

Absolute value for fractional flux error describing the standard deviations as a fraction of the covariance $\overline{w^{\prime} \chi_{c}^{\prime}}$ were calculated as

$\mathrm{AFFE}=\left|\frac{\sigma_{F}}{\overline{w^{\prime} \chi_{c}^{\prime}}}\right|$

AFFE illustrates how big fraction of the measured flux can be a product of random uncertainty, which is related to sampling and instrumental noise. If AFFE values are below one, the measured flux values are statistically significant.

Random uncertainty related to instrumental noise $\left(\sigma_{\text {inst }}\right)$ was estimated with a method proposed by Billesbach (2011). It is based on minimizing the correlation between the time series $w$ and $\chi_{c}$ by randomly shuffling one of them. This corresponds to removing the signal related to turbulent flux from the measurements. After shuffling, covariance between $w$ and $\chi_{c}$ is only related to instrumental noise (Billesbach, 2011).

$\sigma_{\text {inst }}=\frac{1}{n_{\mathrm{s}}} \sum_{i=1}^{n} w^{\prime}(i) \chi_{c_{\text {shuf }}^{\prime}}^{\prime}(i)$

where vector $\chi_{c}^{\prime}{ }_{\text {shuf }}^{\prime}$ contains all the measurements in time series $\chi_{c}{ }^{\prime}$ but the values are in random order. In this study $\sigma_{\text {inst }}$ was calculated eight times for every $30 \mathrm{~min}$ averaging period and the mean of the absolute values of these eight estimates for $\sigma_{\text {inst }}$ were used to estimate random uncertainty related to instrumental noise. $\sigma_{\text {inst }}$ was calculated eight times in order to reduce uncertainty of instrumental noise estimate.

\subsection{Gap filling procedure}

In this study, methane flux was parameterized using peat temperature by assuming an exponential dependence (Conrad, 1989):

$F_{\mathrm{CH}_{4} \text {, daily }}=a b^{\left(T_{\mathrm{p}, \text { daily }}-10\right) / 10}$

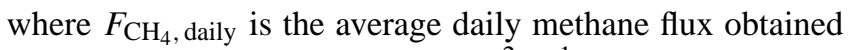
from the four instruments in $\mathrm{mg} \mathrm{m}^{-2} \mathrm{~h}^{-1}$ and $T_{\mathrm{p}}$, daily is peat temperature $\left({ }^{\circ} \mathrm{C}\right)$ at $35 \mathrm{~cm}$ depth. Values $1.88 \pm 0.03$ and $5.34 \pm 0.22$ were obtained for the coefficients $a$ and $b$, respectively. The values are given with $95 \%$ confidence limits.

Even though correlation between the measured mean daily methane flux and the used gap filling method is significant $\left(r^{2}=0.992\right)$ and root mean square error is low $\left(\mathrm{RMSE}=0.17 \mathrm{mg} \mathrm{m}^{-2} \mathrm{~h}^{-1}\right)$, the parameterization is not able 
to capture the high flux periods, which are observed roughly between days 190 and 210 (Fig. 2). Reason for the sudden drop in mean daily methane flux around day 205 is unclear. Rinne et al. (2007) reported similar phenomenon in their study, which was carried out at the same site, and they hypothesized that it might be caused by the fact that the growth of the methanogenic microbe population exceeds the growth in the available substrates, thus limiting the methane production. However, further studies are needed to confirm this hypothesis.

\section{Results}

\subsection{Data coverage}

The intercomparison campaign was carried out between 1 April and 26 October 2010. None of the methane gas analyzers operated continuously through the entire period (Fig. 2). The open-path Prototype-7700 was in operation for 33 days in the beginning of the campaign. The prototype was not operational after 5 June 2010, due to improperly sealed enclosure, leading first to a hardware malfunction (reset in sampling rate from $10 \mathrm{~Hz}$ to $1 \mathrm{~Hz}$ ) on 5 June and a few days later, to a permanent water damage on 11 June. The water sealing issue was fixed later in the production model by the manufacturer. However, as a result of the water damage, the only period when the methane flux was measured with the prototype was during relatively small fluxes of about $0.5 \mathrm{mg} \mathrm{m}^{-2} \mathrm{~h}^{-1}$. Thus, it is difficult to estimate how it would have performed in measuring during medium and high flux periods in the middle of summer, when the flux was around $3-10 \mathrm{mg} \mathrm{m}^{-2} \mathrm{~h}^{-1}$.

The G1301-f was out of use approximately 40 days at the end of July, beginning of August, when fluxes were largest reaching over $10 \mathrm{mg} \mathrm{m}^{-2} \mathrm{~h}^{-1}$. Starting from 15 August the pressure regulation of G1301-f measurement cell did not function properly. Reason for this was the obstruction of an internal filter. Due to the fact that the internal filters were difficult to replace with new ones, the clogged internal filter was removed and replaced with an external Pall Acro 50 filter which is easier to handle. From the 26 August onwards the instrument was back in operation. However, reason for the missing data before 15 August is still unclear. One possible cause is that temperature in the cabinet which housed the closed-path gas analyzers was too high by the end of July and beginning of August, which might have caused G1301-f to be unstable, and lose the data. TGA-100A was taken away from the site at the middle of August. The fact that the instruments were not operating continuously at the same time should be kept in mind when examining and assessing the results, especially for the short operating time of Prototype-7700.

Flux data coverage of the four gas analyzers was estimated during a period when they all functioned properly, between 17 April and 17 May. All methane flux data was discarded if

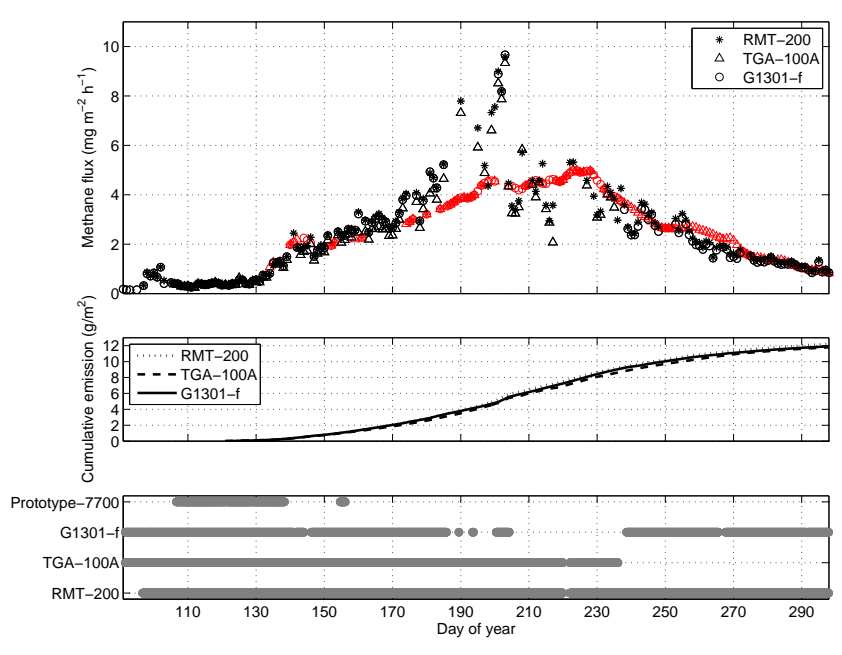

Fig. 2. Gap filled daily averaged methane flux is shown in the upper part, cumulative methane emission estimated from three gas analyzers is shown in the middle part and the periods when the methane gas analyzers were working are shown in the bottom part of the figure. Black and red markers in the upper part represent measured and gap filled values, respectively.

friction velocity was below $0.1 \mathrm{~m} \mathrm{~s}^{-1}$, resulting in 164 halfhourly points to be discarded between 17 April and 17 May. Magnitude of methane flux showed rapid decrease after friction velocity dropped below this threshold (not shown) as also reported for $\mathrm{CO}_{2}$ by Goulden et al. (1996) and others.

The post-processing software also examined Prototype7700 measurements when RSSI (Received Signal Strength Indicator) describing cleanliness of the mirrors had a mean value below threshold of 20 . This threshold was reached on 120 half-hours which were then discarded. Also, the amount of spikes, i.e. outliers, in raw $\mathrm{CH}_{4}$ concentration data and mean half-hourly value of $\mathrm{CH}_{4}$ concentration were used in detecting and discarding additional erroneous data. These criteria discarded 104 and 6 additional half-hours, respectively. Including discarded sonic anemometer data, the total of 395 half-hours were removed from Prototype-7700 dataset during the selected period, which was approximately 140 half-hourly points more than for the three closed-path gas analyzers (Table 2). On the whole, the open-path prototype produced least amount of data during the selected period mostly due to the fact that the measurements were done in an open cell which is vulnerable to the precipitation.

Eddy covariance data were also flagged with three different quality flags according to stationarity criteria proposed by Foken and Wichura (1996). Flags 0, 1 and 2 represent data with good, mediocre and bad quality, respectively. RMT-200 and G1301-f produced the most of high quality flux data (flag 0 in Table 2) during this 30-day-period. Both of them produced data approximately $77 \%$ of time which can be categorized as good data. For TGA-100A this percentage is $61 \%$ and for Prototype- 7700 it is $56 \%$. For RMT-200 and G1301-f 

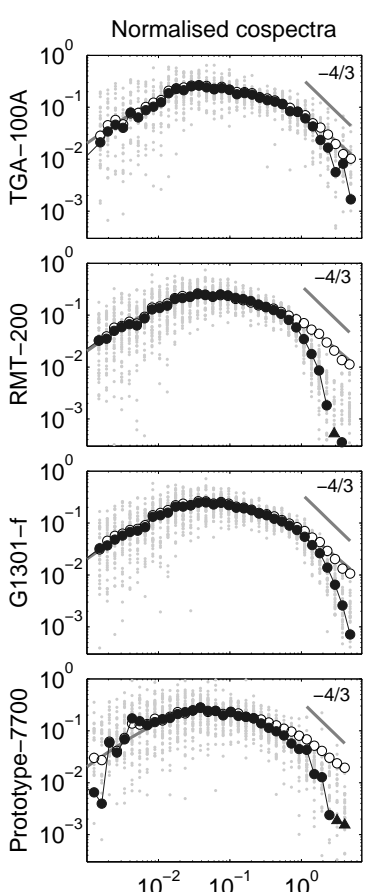

Normalized frequency $n\left(n=f\left(z_{r}-d\right) / U\right)$ Normalized frequency $n\left(n=f\left(z_{r}-d\right) / U\right)$

Fig. 3. Frequency weighted, normalized cospectra and power spectra plotted against normalized frequency $n$. The ensemble averaged methane and temperature cospectra and power spectra are shown with black and white dots, respectively. Black triangles represent negative points of the ensemble averaged methane cospectrum. Small grey dots represent individual methane data from which the mean cospectra and power spectra are calculated from. Straight line in the figures on the left indicates a slope of $-4 / 3$ (Kaimal et al., 1972). Lower and upper straight lines in the figures on the right correspond to ideal slope of $-2 / 3$ and 1 , respectively. Slope of 1 is a sign of white noise (Kaimal and Finnigan, 1994). Cospectra were normalized with corresponding covariance and power spectra were normalized with variance values calculated between frequencies $0.005 \mathrm{~Hz}$ and $0.1 \mathrm{~Hz}$. Spectral data was binned into 35 logarithmically evenly spaced bins before plotting. For Prototype-7700 data was selected from period 17 April-17 May, when methane flux was on average $0.5 \mathrm{mg} \mathrm{m}^{-2} \mathrm{~h}^{-1}$, while for other gas analyzers the data was selected from period 9-29 June, when methane flux was on average $3.4 \mathrm{mg} \mathrm{m}^{-2} \mathrm{~h}^{-1}$.

the amount of data flagged with 0 has a noticeable diurnal variation: around midday almost all the measurements are flagged with 0 , at night the amount of good data is smaller and the amount of data flagged with 1 and 2 slightly increases. The minimum for the amount of data flagged with 0 is reached around 2.30 a.m. when only $45 \%$ of RMT- 200 and G1301-f data are flagged with 0. Interestingly, TGA-100A and Prototype-7700 do not show a pronounced diurnal variation for data quality.

\subsection{Spectral characteristics}

Figure 3 shows ensemble averaged, normalized and frequency weighted cospectra and power spectra received from the four methane gas analyzers. For Prototype-7700 data was selected from period 17 April-17 May while for others data was selected from period 9-29 June. Data was selected according to following criteria: stratification was unstable, data was flagged with quality flag 0 , wind speed was between
Table 2. Amount of data obtained between 17 April and 17 May is given in the first two rows and in the three next rows the data is divided into bins according to data quality. Maximum number of data points during this period is 1440 . Data with flag 0 include those periods when flux stationarity test Foken and Wichura (1996) was smaller than 0.3 . Flag 1 corresponds to those periods when stationarity test was between 0.3 and 1 and flag 2 corresponds to stationarity test with value larger than 1 .

\begin{tabular}{lrrrr}
\hline & RMT-200 & G1301-f & TGA-100A & Prototype-7700 \\
\hline Data (points) & 1178 & 1173 & 1141 & 1045 \\
Data (\%) & 82 & 81 & 79 & 73 \\
\hline Flag 0 (\%) & 77 & 77 & 61 & 56 \\
Flag 1 (\%) & 4 & 3 & 13 & 12 \\
Flag 2 (\%) & 1 & 1 & 5 & 5 \\
\hline
\end{tabular}

$1.5 \mathrm{~ms}^{-1}$ and $4 \mathrm{~ms}^{-1}$ and methane flux was directed upwards. In other words, only periods with well-developed turbulence and unstable conditions were selected. It must be pointed out that this selection of data was done for each methane gas analyzer individually and thus the ensemble averaged methane cospectra are not calculated from the same runs, rather the figure shows the ensemble average calculated from best available data for each gas analyzer.

According to scalar similarity assumption, all normalized scalar cospectra, plotted against the normalized frequency $n$, should collapse into one curve. In other words, temperature and methane cospectra should look the same in Fig. 3. Therefore, by comparing methane cospectra and temperature cospectra with each other, it is possible to assess how well the methane gas analyzers are able to measure methane flux related to different sizes of eddies. Since sonic anemometers can measure the kinematic heat flux and thus scalar cospectra more accurately than the gas analyzers, the temperature cospectra should be closer to the theoretical scalar cospectrum, and can be used as a reference for other scalar cospectra. Overall, all ensemble averaged methane cospectra and temperature cospectra agree well. $\mathrm{CH}_{4}$ flux cospectra from all four methane gas analyzers follow the temperature cospectra at lower frequencies, but at higher frequency they start to fall below the $w^{\prime} T^{\prime}$ cospectra. This damping of high frequency signal is specific to an instrument and setup, and its effect on the magnitude of methane flux can be corrected. This correction and its magnitude are explained in detail in Sect. 3.4.1. From Fig. 3, it is evident that dampening of high frequency signal is most pronounced for RMT-200 cospectra.

Ensemble-averaged and frequency-weighted power spectra of methane and temperature are shown on the right hand side of Fig. 3. The high frequency of measured methane power spectra are greatly affected by white noise during period 17 April-17 May (shown only for Prototype-7700 in Fig. 3), when the methane flux was relatively low. However, the white noise seen in power spectra does not contribute to the covariance due to the fact that white noise in methane 

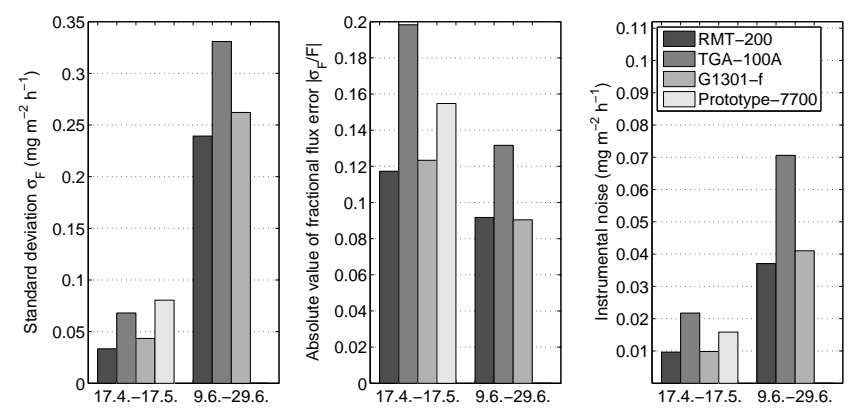

Fig. 4. From left to right: standard deviation of the covariances, absolute value of fractional flux error $\left(\left|\sigma_{F} / F\right|\right)$ and instrumental noise. Median values for these three statistical parameters were calculated during two separate periods. Fractional flux error is calculated as a ratio between the standard deviations and the flux values. Instrumental noise was estimated using method proposed by Billesbach (2011).

concentration measurements does not correlate with vertical wind speed time series; rather it just increases the random error of the measurement.

During period 9-29 June, when Prototype-7700 was already out of operation, the methane fluxes were from 10 to 12 time higher than during the period 17 April-17 May, and the ensemble averaged power spectra seem to follow the temperature power spectra better (the upper three plots on the right hand side in Fig. 3). G1301-f power spectra does not show any sign of white noise, while RMT-200 power spectra starts to be dominated by white noise when $n \approx 2.2$, corresponding to frequency $1.6 \mathrm{~Hz}$. At slightly lower frequencies also dampening of RMT-200 signal can be detected. TGA-100A ensemble averaged methane power spectra starts to deviate from the temperature ensemble averaged power spectra already when the normalized frequency is around 0.4 $(0.3 \mathrm{~Hz})$ (Fig. 3). White noise had the most significant effect on TGA-100A of all instruments. TGA-100A ensemble averaged power spectra deviated from temperature power spectra also at low frequencies during both periods, possibly as a result of the drift in the signal.

\subsection{Random error estimation}

The median standard deviations of the covariances related to four methane gas analyzers during two different periods are shown on the left of Fig. 4. The standard deviations represent the uncertainty caused by instrumental noise and one-point sampling of the flux and they were calculated according to Eq. 11. TGA-100A and Prototype-7700 give largest standard deviations for the covariances, implying larger random errors. During the first period (17 April-17 May) they gave almost twice the standard deviation of that for RMT-200 and G1301-f. Random error of the flux measurements is related to the magnitude of measured flux, i.e., high flux leads to high random error. Since open-path instruments are subject
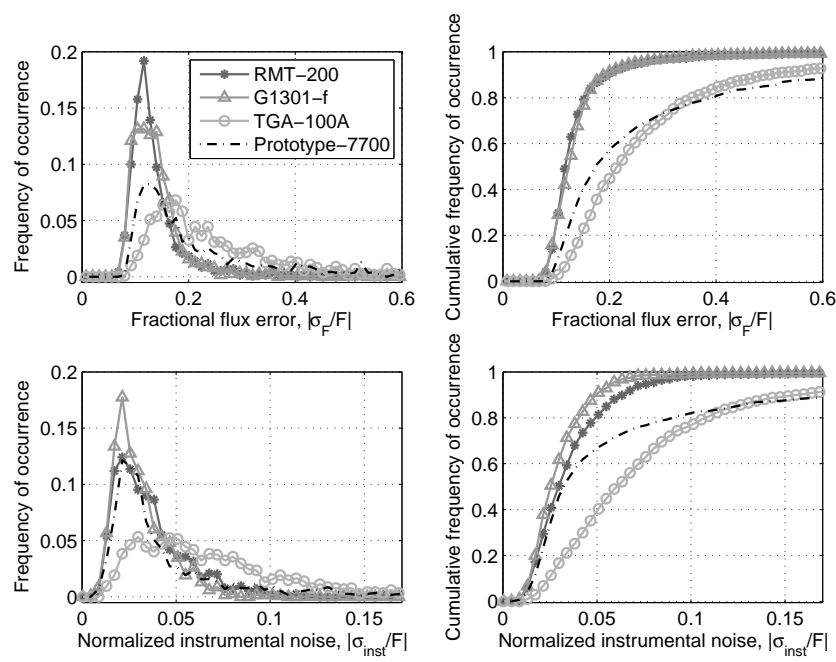

Fig. 5. Top row: Distribution curves of absolute value of fractional flux error $\left(\left|\sigma_{F} / F\right|\right)$ (left plot) and cumulative sums of relative frequency of occurrence (right plot). Bottom row: the same as the top row, but for normalized instrumental noise $\left(\left|\sigma_{i n s t} / F\right|\right)$. Frequency of occurrence is normalized with the amount of measurements and, thus the curves on the left give relative amount of data in each bin. Only periods when all the methane gas analyzers were working were used.

to the full water vapor and temperature effects, and to the full WPL equation, and closed-path instruments are not subject to these, the raw uncorrected Prototype-7700 methane flux shows uptake of methane in the middle of day, while the closed-path instruments show weak emission. Therefore, random error related to magnitude of the raw flux is expected to be higher for the open-path Prototype-7700 than for the closed-path instruments shown in Fig. 4 (left plot). During the second period (9 June-29 June) the standard deviations were overall approximately five times larger than during the first period. This was expected due to the fact that the measured flux was significantly larger during the second period.

In addition to standard deviations, which describe the random uncertainty caused by sampling and instrumental noise, the random uncertainty caused purely by instrumental noise was estimated according to Eq. (15). Magnitude of instrumental noise is a good measure of instrument performance. The median values are plotted in Fig. 4 (right plot). Uncertainty caused by instrumental noise increases when the flux magnitude increases. This can be seen if the noise levels during the two periods are compared, because the methane flux was on average larger during the second period. Again, RMT200 and G1301-f performed the best during both periods by having the smallest mean values for the instrumental noise, while TGA-100A had the highest.

Lower part of Fig. 5 shows distribution of normalized instrumental noise for the four methane analyzers during the first period (17 April-17 May). All the distribution curves show an asymmetric shape: the curves peak at low values 
and then they have a tail reaching up to the higher values. The distribution curves of RMT-200, G1301-f and Prototype7700 peak at 0.02 , whereas for TGA-100A the most common value is closer to 0.03 , meaning that instrumental noise is 2 or $3 \%$ of the measured covariance. For TGA-100A, however, no definite peak in the distribution can be seen and the distribution is wider than for the other gas analyzers. From cumulative frequency of occurrence plot (bottom right plot in Fig. 5) it can be seen that $80 \%$ of the values for RMT-200, G1301-f, Prototype-7700 and TGA-100A are below 0.05, $0.04,0.09$ and 0.11 , respectively. For Prototype-7700 most of the values are between 0.01 and 0.04 , similarly to RMT200 and G1301-f, but higher values are more common.

Absolute values for fractional flux errors (AFFE) were calculated according to Eq. (14). RMT-200 and G1301-f give the smallest average values for AFFE during the both periods (Fig. 4, central plot). AFFE from Prototype-7700 is approximately 0.03 higher than from RMT-200 or G1301-f. AFFE of TGA-100A was consistently higher than for the other three instruments due to higher standard deviation.

Distribution of AFFE values is shown in the upper part of Fig. 5, similarly to the distribution of normalized instrumental noise. From cumulative frequency of occurrence shown on the right in Fig. 5, it is evident that approximately $90 \%$ of the RMT-200 and G1301-f AFFE values are below 0.19 and the most common value is approximately 0.12 . The distributions of AFFE values are very narrow; absolute values of fractional flux error values above 0.3 are rarely witnessed.

Distributions of TGA-100A and Prototype-7700 AFFE values are wider than for the two previous gas analyzers (Fig. 5). About $90 \%$ of the AFFE values are below 0.5 for TGA-100A and below 0.63 for Prototype-7700. The most common value for Prototype- 7700 is 0.13 , while for TGA$100 \mathrm{~A}$ it is 0.18 . The distribution of Prototype-7700 AFFE values peaks at the same place as distribution of RMT-200 and G1301-f values, however high AFFE values are more common for Prototype-7700. AFFE of Prototype-7700 and TGA-100A methane flux measurements depend on the magnitude of the flux. Most of the AFFE values are below 0.5, however when the flux falls below $0.2 \mathrm{mg} \mathrm{m}^{-2} \mathrm{~h}^{-1}$, the AFFE values start to rise. For RMT-200 and G1301-f such a dependence is not detected. This might be partly caused by the fact that they did not measure as small fluxes as the other instruments and thus the high AFFE values that are related to small fluxes are not detected. If only moments when absolute value of raw uncorrected methane flux was larger than $0.3 \mathrm{mg} \mathrm{m}^{-2} \mathrm{~h}^{-1}$ are used, the median AFFE values are 0.12 , $0.13,0.17$ and 0.15 for RMT-200, G1301-f, TGA-100A and Prototype-7700, respectively.

\subsection{Systematic error estimation}

Unbiased correct information on the reference magnitude of the real flux is needed in order to estimate how much the measured methane flux deviates from the real methane flux.
Such information cannot be obtained, as all the measurements may have errors. Nonetheless, certain measurement system and data processing induced systematic errors have been identified and they can be corrected. These corrections are presented in the following subsections.

\subsubsection{Spectral corrections}

As mentioned in Sect. 3.2, the high frequency end of methane flux cospectra is usually attenuated, meaning that it falls below temperature flux cospectra. High frequency part of methane flux cospectra divided with temperature cospectra are shown in Fig. 6. The grey line shows transfer function given in Eq. (4) with corresponding response time. This grey line should follow the ensemble averaged methane cospectrum divided with temperature cospectrum (black dots) and the high frequency part of spectral correction can be estimated by integrating over the transfer function.

Response times were estimated experimentally using a method presented in Aubinet et al. (2000). As a result, mean response times of $0.16 \mathrm{~s}, 0.08 \mathrm{~s}, 0.08 \mathrm{~s}$ and $0.16 \mathrm{~s}$ were obtained for RMT-200, TGA-100A, G1301-f and Prototype7700 , respectively. These values correspond to cut-off frequencies of $0.99 \mathrm{~Hz}, 1.99 \mathrm{~Hz}, 1.99 \mathrm{~Hz}$ and $0.99 \mathrm{~Hz}$, respectively. TGA-100A and G1301-f have the shortest response time, meaning that they respond the best to changes in methane concentration. However, it must be kept in mind that not only the instrument response, but also the rest of the measurement system (sampling tube and filter, response of sonic anemometer, spatial sensor separation) has an effect on the total system response time. Therefore, the obtained response times describe not only the instrument response, but also the ability of the whole system to measure high frequency turbulent fluctuations. Longer response time of Prototype-7700 is rather surprising, because usually open-path instruments have a short response due to the absence of intake tubes and filters. The long response of Prototype- 7700 may be a result of the positioning of this instrument substantially below the rest of the intakes, $1.1 \mathrm{~m}$ above the surface of the wood log structure, in conjunction with $0.45 \mathrm{~m}$ vertical separation between the instrument and the sonic anemometer.

Magnitudes of the spectral corrections are given in Table 3 as fractions of the raw, uncorrected methane flux. Diurnal variations of data with and without spectral corrections are shown in Fig. 7 for RMT-200 and Prototype7700 . Spectral corrections always increase the absolute value of the flux, regardless of what the direction is of the flux. Spectral corrections are done before adding WPL terms or doing spectroscopic corrections, thus spectrally-corrected fluxes are still affected by density fluctuations and spectroscopic effects. This means that for Prototype-7700, RMT200 and G1301-f spectral corrections are done for datasets that follow dotted lines in Fig. 7. For Prototype-7700 the corrections increase the magnitude of negative and positive methane fluxes (Table 3 and Fig. 7) during daytime and 

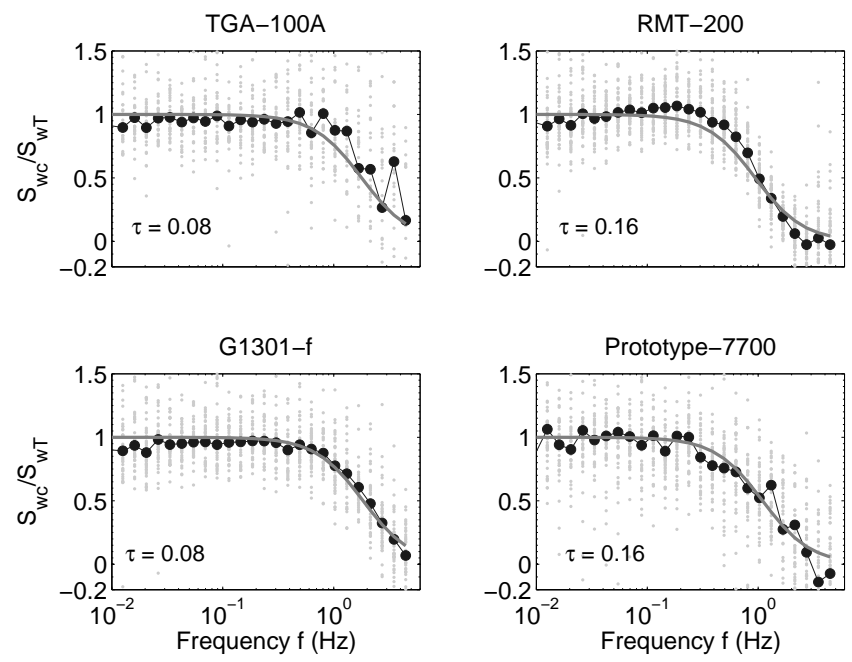

Fig. 6. Transfer function determined from measured cospectra. Grey line is transfer function (Eq. 4), black dots connected with a line represents mean methane cospectrum $\left(S_{w c}\right)$ divided with mean temperature cospectrum $\left(S_{w T}\right)$, grey dots show individual methane cospectra divided with corresponding temperature cospectra. Response times related to each gas analyzer are shown in the figure. Cospectral data was binned into 35 logarithmically evenly spaced bins before plotting. For Prototype-7700 data were selected from a period 17 May-17 April using the same selection criteria as in Sect. 3.2, while for the other gas analyzers data were selected from a period 9-29 June.

nighttime, respectively. Thus, spectral corrections partly cancel the effect of WPL terms and spectroscopic corrections on Prototype-7700 methane fluxes due to the fact that they have an opposing effect on the flux. If Tables 3 and 4 are compared, it is evident that for Prototype-7700 WPL terms and spectroscopic correction are more important than spectral corrections. The correction has the smallest effect on TGA-100A and G1301-f methane fluxes (Table 3). This is expected due to the fact that they had a shorter response time than Prototype-7700 and RMT-200.

\subsubsection{Sensitivity to water vapor and temperature fluctuations}

TGA-100A was connected to a drier and thus for this instrument no density or spectroscopic corrections are needed. Significance of WPL terms (Webb et al., 1980) and the new spectroscopic correction are assessed for G1301-f, RMT-200 and Prototype-7700 in this section using data obtained between 17 April-17 May.

For open-path gas analyzers the WPL terms are significantly more important than for closed-path instruments due to the fact that for closed-path gas analyzers the temperature fluctuations are dampened by the sampling tube prior to air sample arrival to the measurement cell. Thus, we can expect that the WPL terms and the spectroscopic correction will be
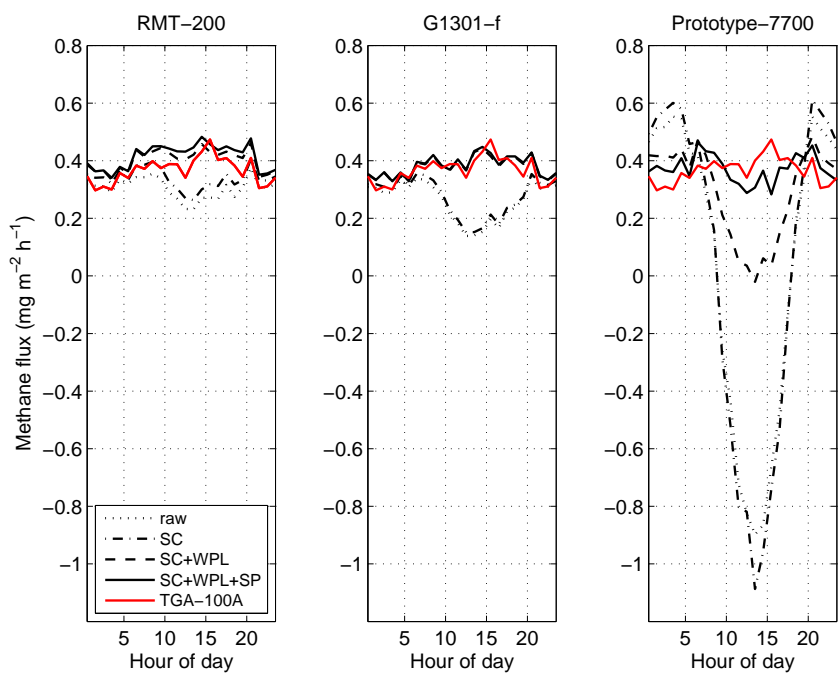

Fig. 7. Diurnal variations of RMT-200, G1301-f and Prototype7700 methane fluxes at different stages of post-processing. Dotted line represents diurnal variation of raw, uncorrected data. SC, WPL and SP correspond to spectral corrections, WPL terms and spectroscopic correction, respectively. Therefore, black line shows the diurnal variation of fully corrected, final flux. Diurnal variation of TGA$100 \mathrm{~A}$ methane flux is shown for comparison with red line. Only data between 17 April and 17 May were used. Flux data flagged with quality flag 0 was selected for all plots individually and thus the red lines are not exactly the same in these three figures.

Table 3. Magnitude of spectral corrections given as percentages of raw uncorrected covariance. Positive and negative values mean that the correction increases upward and downward directed flux, respectively. Daytime was defined as periods when the Sun's elevation angle was above $0^{\circ}$ and nighttime was defined as periods when it was below $-3^{\circ}$. Only data from a period when all the instruments were working (17 April-17 May) was used in calculating the values in the table.

\begin{tabular}{lrrrr}
\hline & RMT-200 & G1301-f & TGA-100A & Prototype-7700 \\
\hline All data (\%) & 11.1 & 5.1 & 5.4 & 3.5 \\
Daytime (\%) & 12.1 & 5.8 & 6.2 & -3.6 \\
Night time (\%) & 9.1 & 4.0 & 4.1 & 7.3 \\
\hline
\end{tabular}

larger for Prototype-7700 methane fluxes than for RMT-200 or G1301-f. Spectroscopic and WPL terms were applied according the method presented in Sect. 2.3.2. For Prototype7700 the coefficients $A, B$ and $C$ in Eq. (6) were obtained from look-up tables distributed with the instrument. During the measurement campaign the approximate ranges for $A, B$ and $C$ were 0.94 to $0.99,1.42$ to 1.46 and 1.21 to 1.34 , respectively.

As expected for open-path design, WPL terms were large in the open-path methane fluxes from Prototype-7700. The terms increase the flux by $0.20 \mathrm{mg} \mathrm{m}^{-2} \mathrm{~h}^{-1}$, on average. However, this difference has a clear diurnal variation. At daytime (Sun's elevation angle larger than $0^{\circ}$ ), it is 
Table 4. WPL terms and spectroscopic correction given as percentages of the uncorrected raw covariance. Positive and negative values mean that the correction increases the upward and downward directed flux, respectively. Daytime was defined as those periods when the Sun's elevation angle was above $0^{\circ}$ and nighttime as those periods when it was below $-3^{\circ}$. Only data from a period when all the instruments were working (17 April-17 May) was used in calculating the values in the table.

\begin{tabular}{lrrrr}
\hline & & RMT-200 & G1301-f & Prototype-7700 \\
\hline \multirow{2}{*}{ All data } & WPL terms (\%) & 15.3 & 21.1 & 80.1 \\
& Spectroscopic correction (\%) & 3.2 & 0.9 & 23.6 \\
Daytime & WPL terms (\%) & 23.9 & 38.4 & 105.1 \\
& Spectroscopic correction (\%) & 5.0 & 1.2 & 31.8 \\
Night time & WPL terms (\%) & 4.5 & 6.9 & -27.9 \\
& Spectroscopic correction (\%) & 0.9 & 0.6 & -8.5 \\
\hline
\end{tabular}

approximately $0.37 \mathrm{mg} \mathrm{m}^{-2} \mathrm{~h}^{-1}$ and at nighttime (Sun's elevation angle below $-3^{\circ}$ ) it is around $-0.14 \mathrm{mg} \mathrm{m}^{-2} \mathrm{~h}^{-1}$, meaning that the correction diminishes the fluxes at night. Spectroscopic correction is not as significant as WPL terms for Prototype-7700 methane fluxes: on average fluxes corrected for the spectroscopic effects and density fluctuations are $0.06 \mathrm{mg} \mathrm{m}^{-2} \mathrm{~h}^{-1}$ larger than only WPL-corrected fluxes. However, also spectroscopic correction has a diurnal variation and the difference is $0.11 \mathrm{mg} \mathrm{m}^{-2} \mathrm{~h}^{-1}$ at daytime, while at nighttime it is $-0.04 \mathrm{mg} \mathrm{m}^{-2} \mathrm{~h}^{-1}$. For the closed-path gas analyzers RMT-200 and G1301-f the significance of WPL terms and spectroscopic correction are much smaller as expected for a closed-path design. WPL terms increase the fluxes on average by $0.05 \mathrm{mg} \mathrm{m}^{-2} \mathrm{~h}^{-1}$ and $0.07 \mathrm{mg} \mathrm{m}^{-2} \mathrm{~h}^{-1}$, respectively. If daytime and nighttime are examined separately, this increase is $0.08 \mathrm{mg} \mathrm{m}^{-2} \mathrm{~h}^{-1}$ and $0.01 \mathrm{mg} \mathrm{m}^{-2} \mathrm{~h}^{-1}$ for RMT-200 and $0.11 \mathrm{mg} \mathrm{m}^{-2} \mathrm{~h}^{-1}$ and $0.02 \mathrm{mg} \mathrm{m}^{-2} \mathrm{~h}^{-1}$ for G1301-f, respectively. Significance of spectroscopic correction is smaller than the significance of WPL terms: on average spectroscopic correction increased the fluxes for RMT-200 and G1301-f by $0.01 \mathrm{mg} \mathrm{m}^{-2} \mathrm{~h}^{-1}$ and $0.003 \mathrm{mg} \mathrm{m}^{-2} \mathrm{~h}^{-1}$, respectively. At daytime and nighttime this increase is $0.02 \mathrm{mg} \mathrm{m}^{-2} \mathrm{~h}^{-1}$ and $0.003 \mathrm{mg} \mathrm{m}^{-2} \mathrm{~h}^{-1}$ for RMT-200 and $0.003 \mathrm{mg} \mathrm{m}^{-2} \mathrm{~h}^{-1}$ and $0.002 \mathrm{mg} \mathrm{m}^{-2} \mathrm{~h}^{-1}$ for G1301-f, respectively. In Table 4 these values are listed as percentages of the uncorrected raw covariance.

The corrected fluxes were compared with methane flux calculated from TGA-100A data. This dataset should be almost free from density fluctuations and spectroscopic effects, since the closed-path analyzer was connected to a drier, while sampling line dampened temperature fluctuations. Therefore, in theory with this kind of comparison it is possible to verify and assess the performance of WPL terms and spectroscopic corrections that were applied to RMT-200, G1301-f and Prototype-7700 data. Diurnal variation of TGA-100A methane flux is shown in Fig. 7 with diurnal variations of RMT-200, G1301-f and Prototype-7700 methane fluxes at different stages of post-processing. The diurnal variation of fully corrected flux agrees better with TGA-100A than the diurnal variation of not corrected flux. This is true for all three gas analyzers, RMT-200, G1301-f and Prototype-7700.
Therefore, it can be said that both of the corrections are modifying the flux data into the right direction. For open-path Prototype-7700 WPL terms alone are not enough, due to the fact that diurnal variation of WPL-corrected Prototype-7700 flux differs quite a lot from the TGA-100A data at daytime. However, from Fig. 7 and Table 4 it is evident that the WPL terms are more significant for Prototype-7700 than the spectroscopic correction. After correcting the Prototype-7700 flux data with WPL terms high uptake of methane at daytime, i.e., flux directed downwards, is turned into weak emission which is more plausible at this site. Both corrections also increase the correlation between TGA-100A methane flux data and RMT-200, G1301-f and Prototype-7700 data. For RMT-200 methane flux data the correlation coefficient $(r)$ with TGA-100A methane flux data is $0.75,0.87$ and 0.88 without WPL terms or spectroscopic correction, with WPL terms and with both corrections, respectively. For G1301$\mathrm{f}$ methane flux data these correlation coefficients are 0.63 , 0.89 and 0.89 and for Prototype-7700 they are $-0.11,0.10$ and 0.22 , respectively.

\subsection{Diurnal variation and methane flux magnitude}

Median diurnal variation of methane flux obtained from the four methane gas analyzers are shown in Fig. 8. Only data measured between 17 April and 17 May were used so that the figure can be compared with Table 5. The methane fluxes agree well at night. All the four measurement systems show that the flux is on average between 0.3 and $0.4 \mathrm{mg} \mathrm{m}^{-2} \mathrm{~h}^{-1}$. While the measured methane fluxes agree at night, at daytime there is a bigger difference between them. Rinne et al. (2007) did not find any diurnal variation in methane flux at this measurement site. In our study, none of the four gas analyzers show a statistically significant diurnal pattern for the methane flux (Fig. 8), which is in line with Rinne et al. (2007). For Prototype-7700 it is difficult to assess the validity of methane flux diurnal variation due to high variation in the data.

By comparing the measured methane flux to the mean value of all the methane flux values, it is possible to assess the magnitude of the methane flux relative to each other. This kind of comparison can be seen in Tables 5 and 6 . 
Table 5. Average difference between methane flux obtained from one instrument and mean flux obtained from the four instruments between 17 April and 17 May. All the four methane gas analyzers were working during this period. If difference and relative difference are negative, the flux obtained from that certain instrument is smaller than the mean flux obtained from all of the instruments. Only data flagged with quality flag 0 was used.

\begin{tabular}{lrrrr}
\hline & RMT-200 & G1301-f & TGA-100A & Prototype-7700 \\
\hline Flux $\left(\mathrm{mg} \mathrm{m}^{-2} \mathrm{~h}^{-1}\right)$ & 0.448 & 0.424 & 0.395 & 0.379 \\
Difference $\left(\mathrm{mg} \mathrm{m}^{-2} \mathrm{~h}^{-1}\right)$ & 0.037 & 0.012 & -0.017 & -0.032 \\
Relative difference $(\%)$ & 8.2 & 2.9 & -4.2 & -8.6 \\
\hline
\end{tabular}

RMT-200 gives the highest methane fluxes between 17 April and 17 May $\left(0.448 \mathrm{mg} \mathrm{m}^{-2} \mathrm{~h}^{-1}\right)$, while Prototype-7700 gives the lowest $\left(0.379 \mathrm{mg} \mathrm{m}^{-2} \mathrm{~h}^{-1}\right)$.

\subsection{Season-long performance}

Figure 9 shows how well the methane flux estimates from the four methane gas analyzers agree with each other. Methane flux from G1301-f was selected as a reference for the three other gas analyzers because of two reasons: the random error was relatively small (Sect. 3.3) and the corrections to the flux measurements are small.

RMT-200 and G1301-f methane fluxes agree well during low flux periods and high flux periods (Fig. 9). This can be seen from the fact that all the points are crowded in a narrow band near the 1:1 line and the scattering of the points is increased neither in the low flux nor in the high flux end of the figure. A linear regression was fitted to the measurements and the fit can be seen in the figure. Slope (1.004) and intercept (0.049) imply of good match between datasets. $95 \%$ confidence intervals for the coefficient estimates are 1.003 and 1.006 for the slope and 0.045 and 0.054 for the intercept. The correlation coefficient between the datasets is high $(r=0.999)$ and the root-mean-square error is low $(\mathrm{RMSE}=0.138)$. Functioning of the gas analyzers RMT-200 and G1301-f are based on quite similar basic principle and this might explain the good correlation.

G1301-f does not agree as well with TGA-100A as it does with RMT-200 (Fig. 9). The slope of the fitted linear regression is 0.894 (95\% confidence intervals are 0.884 and 0.904 ) and it is clearly below the ideal slope of $1: 1$ line. The intercept is quite near zero with value of 0.011 (95\% confidence intervals are -0.021 and 0.042 ). However, most of the points follow the $1: 1$ line, but few outliers cause the fit to differ from the ideal $1: 1$ line. This can also be seen if the values of the residual are examined: they are mostly positive when the flux is large. If the fit describes the measurements well, the residual values should vary around zero, as in the case of RMT-200 and G1301-f methane fluxes. Thus, it can be argued that the TGA-100A and G1301-f methane flux datasets agree better than the slope of the fitted linear regression implies, at least when the flux is not exceedingly large. The correlation between the TGA-100A and G1301$\mathrm{f}$ datasets $(r=0.956)$ is smaller than between RMT-200 and
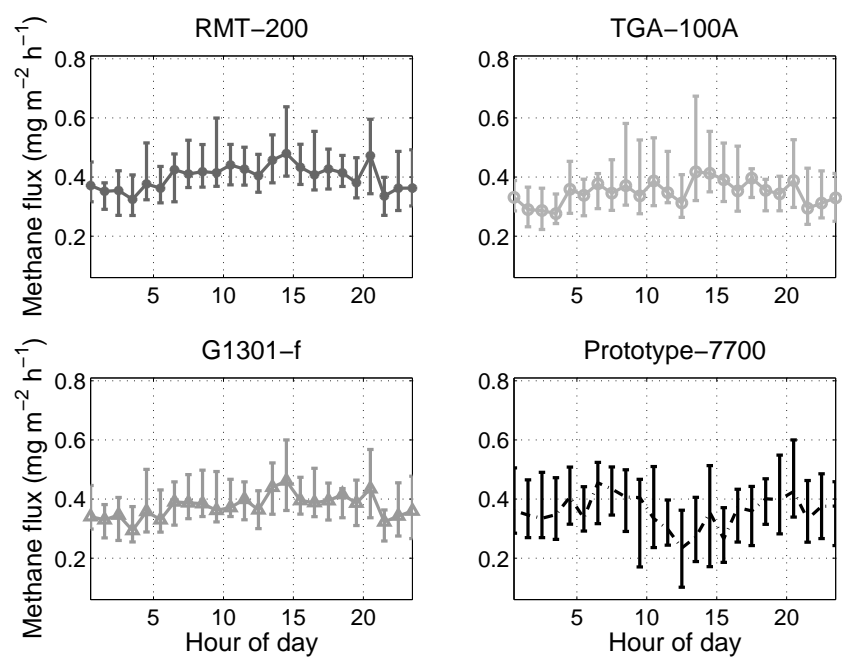

Fig. 8. Median diurnal variation of final fully corrected methane flux obtained from the four methane gas analyzers. Only data from a period when all the instruments were working (17 April-17 May) were used. Data from this period was selected so that the methane fluxes were given quality flag 0 . Error bars denote the interquartile range around the median values.

G1301-f methane fluxes and the root-mean-square error is higher $(\mathrm{RMSE}=0.765)$. There was quite a lot of scattering in TGA-100A methane flux data and thus the points are not grouped as a narrow band around the fitted line and RMSE is rather high. The scattering in TGA-100A methane flux data is probably caused by high random error in the measurements (Sect. 3.3).

Also the agreement between Prototype-7700 and G1301-f was assessed (Fig. 9), even though the amount of Prototype7700 measurements is smaller than the amount of data received from the other gas analyzers. Prototype- 7700 was operational only during period with relatively low methane flux, and thus the points in the scatter plot figure are nearzero. However, even though the points are located in a small range of methane flux values, it can be seen that they follow quite well the ideal $1: 1$ line. Fitted linear regression has slope and intercept of 1.064 (95\% confidence intervals are 0.985 and 1.143$)$ and $-0.104(95 \%$ confidence intervals are -0.181 and -0.028 ), respectively. 
Table 6. Same as Table 5, but data was selected from between 9 June and 29 June. Prototype-7700 was out of operation during this period.

\begin{tabular}{lrrr}
\hline & RMT-200 & G1301-f & TGA-100A \\
\hline Flux $\left(\mathrm{mg} \mathrm{m}^{-2} \mathrm{~h}^{-1}\right)$ & 3.159 & 3.104 & 2.759 \\
Difference $\left(\mathrm{mg} \mathrm{m}^{-2} \mathrm{~h}^{-1}\right)$ & 0.151 & 0.097 & -0.248 \\
Relative difference $(\%)$ & 4.8 & 3.1 & -9.0 \\
\hline
\end{tabular}

The correlation coefficient between the Prototype-7700 and G1301-f methane flux datasets is 0.615 and root-meansquare error is 1.021. Low correlation and high RMSE are caused by scatter in the points when G1301-f measured quite low flux. Without these deviations from 1:1 line the correlation would be better. Scatter plots of methane flux data obtained only between 17 May and 17 April are shown on the right in Fig. 9.

Cumulative emission of methane during a part of the campaign (between 1 May and 25 October) was estimated from the data obtained from three closed-path gas analyzers. They functioned with occasional breaks throughout the measurement campaign, while for Prototype-7700 the amount of received data was small, and cumulative flux data were not estimated. Cumulative emission was calculated from mean daily methane fluxes and the mean daily values were calculated from methane flux data which was flagged with quality flag 0 . If less than one third of the measurements in a day fulfilled this criterion, mean daily methane flux was estimated using the dependence between methane flux and peat temperature (Eq. 16) and the same gap filling method was used for all the methane flux measurements. This kind of procedure lead 34, 68 and 103 out of 178 days to be gap filled for RMT200, G1301-f and TGA-100A datasets, respectively. Cumulative methane emission estimated from RMT-200 data was based on measurements the most due to small amount of gap filled days, while TGA-100A had the most gap filled days. In fact, cumulative methane emission estimated from TGA$100 \mathrm{~A}$ data is more based on gap filling than on real measurements, since the amount of gap filled days exceeds the amount of measured days, and thus the value for methane balance estimated from TGA-100A data is a bit dubious.

The mean daily methane flux values show great similarity over the period and the gap filled values follow closely the measured values (upper part in Fig. 2). Only during the extremely high flux period around day of year 200 is not modeled well by the gap filling method. The three estimates for the cumulative emission shown in the middle part of Fig. 2 are almost the same and the amount of overall emitted methane over the period for RMT-200, G1301-f and TGA$100 \mathrm{~A}$ data are $12.3 \mathrm{~g} \mathrm{~m}^{-2}, 11.9 \mathrm{~g} \mathrm{~m}^{-2}$ and $11.8 \mathrm{~g} \mathrm{~m}^{-2}$, respectively. Thus, it can be said that the methane balance obtained from the three gas analyzers is the same even though the amount of gap filled days is not. Overall the daily methane emissions estimated from these three gas analyzers
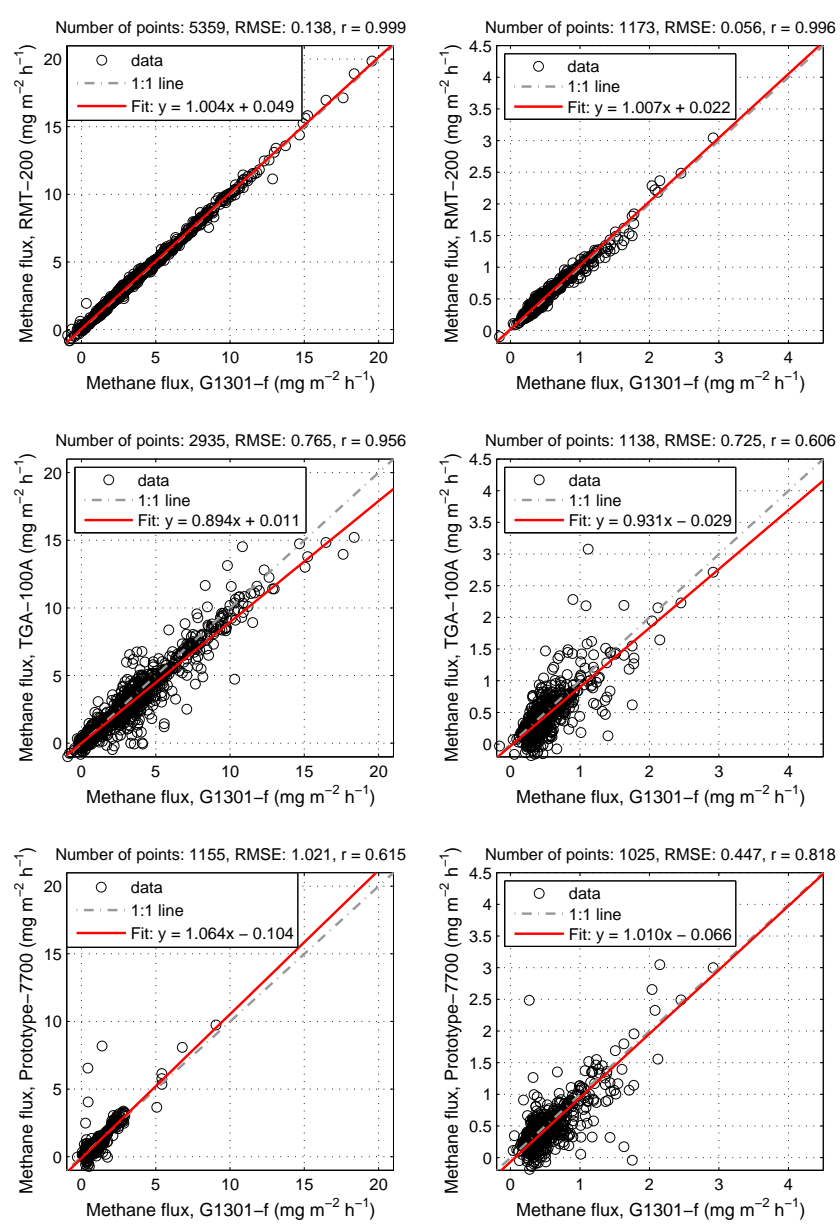

Fig. 9. Scatter plots of methane flux measured with different gas analyzers. Only periods when amount of spikes in a half an hour exceeded 100 were discarded. Number of points in the figure, rootmean-square error and correlation coefficient are given above each figure, respectively. Figures on the left show all the available data and figures on the right are otherwise similar, except data was selected only from period 17 May-17 April. During this period all the instruments were working simultaneously and methane flux was on average $0.5 \mathrm{mg} \mathrm{m}^{-2} \mathrm{~h}^{-1}$.

agree very well and the determination of methane balance does not depend on the selection of the gas analyzer.

\section{Discussion}

In terms of data coverage, the RMT-200 worked well consistently throughout the campaign, while the other instruments were out of operation for various periods. The RMT200 and G1301-f produced, on average, the highest amount of good quality data, followed by the Prototype-7700 which was damaged early in the campaign, preventing season-long methane budget calculations. The prototype damage was a result of an unsealed enclosure, causing permanent rain water damage to the electronics. This issue was subsequently 
resolved during the redesign of the early prototype into a more advanced prototypes, and finally, into a production model. TGA-100A and Prototype-7700 produced less good quality data than RMT-200 and G1301-f, possibly due to instrument related problems, such as contamination of open measurement cell (Prototype-7700) or drift in the signal (TGA-100A). Prototype-7700 data loss could have been further minimized by careful programming of automated selfcleaning and heating mechanisms (available in a production model) and manual cleaning of the mirrors. However, this increases maintenance needs, which may be more difficult at remote sites. Malfunctioning of G1301-f in the middle of summer, possibly caused by too high a temperature in the measurement container, was problematic since during that time methane production was the highest, and thus this period was crucial for estimating annual methane budgets.

Concerning the random errors and instrument noise, the RMT-200 and G1301-f had on average the best performance, followed by the Prototype-7700, and then by TGA-100A. No significant difference was observed in these categories between RMT-200 and G1301-f (Figs. 4 and 5). However, Detto et al. (2011) observed higher instrumental noise for RMT-200 than for the LI-7700 data (production unit in their study) using same methods as in this study. Overall, the fact that all three new gas analyzers show lower instrument noises and smaller random errors than the older TGA$100 \mathrm{~A}$ model highlights the improvement in the performance of the eddy covariance methane analyzers achieved during the last decade. This will eventually lead to more precise methane budget estimates and will enable research at less studied ecosystems with small methane fluxes, such as lakes, forests, deserts, etc.

Speaking of signal attenuation, the three closed-path instruments had the attenuation generally in the range that can be expected for closed-path design (Fig. 6). The attenuation was larger from Prototype-7700, however, McDermitt et al. (2010) disagrees with this study by showing production unit LI-7700 methane flux cospectra with small frequency attenuation. Also Detto et al. (2011) and Dengel et al. (2011) show production unit LI-7700 methane cospectra which are attenuated less than Prototype-7700 cospectra in this study. The likely explanation for a larger attenuation observed in this study is that Prototype-7700 was installed $1.1 \mathrm{~m}$ above wood log structure, and positioned $0.45 \mathrm{~m}$ below the sonic anemometer. The intakes from other analyzers were located above and away from the wooded structure. This likely caused the attenuated cospectra, longer response time, and larger noise and random errors. The size of the open cell may have also contributed to the path averaging of the smaller eddies. Overall, these issues are more related to the measurement setup than to the instrument performance. The one of the main advantages that the open-path design is traditionally thought to have over the closed-path design is that the high frequency attenuation and the resulting spectral corrections are smaller. This is because no intake or filters are required. However, this advantage comes with a drawback of an increased cell contamination, and thus, the increased need of cell cleaning in order to avoid reduced data coverage, lower data quality and higher random errors.

In terms of density and spectroscopic corrections, the open-path Prototype-7700 measurements had large WPL terms (Fig. 7 and Table 4) as expected for an open-path design. Detto et al. (2011) reported that WPL terms were quite important in the open-path measurements and will affect the uncertainty in final flux estimates. In the middle of day, when water vapor and temperature fluxes were high, the WPL terms were of the same order of magnitude as the raw flux. Similarly, spectroscopic corrections were more important for the open-path fluxes than for the closed-path fluxes. However, these do not pose a problem for flux calculations if all the variables needed in the WPL terms and spectroscopic corrections are properly measured and applied. McDermitt et al. (2010) reported that the coefficients A, B and C used in spectroscopic correction should be in the range 0.77-1.00, $1.39-1.42$ and $1.28-1.4$, respectively. In our study, coefficients $B$ and $C$ are slightly outside the range that McDermitt et al. (2010). Reason for the discrepancy between McDermitt et al. (2010) and this study was not found. For closed-path RMT-200 and G1301-f, both WPL terms and spectroscopic corrections were not as significant, and were only dependent on water vapor flux. Therefore, even though the corrections were moderate for RMT-200 and G1301-f fluxes on average, they might have bigger effect on the measurements, when methane flux is low and water vapor flux is high. For G1301$\mathrm{f}$ these corrections can be done easier and with greater confidence than for RMT-200, since the instrument measures water vapor simultaneously with methane, whereas for RMT200 the corrections have to be made using $\mathrm{H}_{2} \mathrm{O}$ from another instrument, such as LI-7000 in this study. This causes some uncertainty to RMT-200 methane fluxes. However, the newer models by Los Gatos Research (LGR) measure also $\mathrm{H}_{2} \mathrm{O}$ and these early $\mathrm{CH}_{4}$ analyzers by LGR, such as RMT-200 in this study, can be retrofitted to include measurement and data reporting of $\mathrm{H}_{2} \mathrm{O}$ (Doug Baer, personal communication).

As for the fully corrected final fluxes, the fact that these fluxes agreed well among all analyzers (Fig. 9), especially RMT-200 and G1301-f, and the methane balance estimates were quite similar, proves that all four tested instruments were well-suited for methane flux measurements using eddy covariance method.

\section{Summary and conclusions}

In this study, the performances of four methane gas analyzers was assessed in terms of suitability for eddy covariance flux measurements. The experiment was conducted from 1 April to 26 October 2012, over a pristine fen in Southern Finland. The four analyzers consisted of three commercially available closed-path units, TGA-100A (Campbell Scientific Inc., 
USA), RMT-200 (Los Gatos Research, USA), G1301-f (Picarro Inc., USA), and an early prototype of open-path design, Prototype-7700 (LI-COR Biosciences, USA). The older established model TGA-100A was used as a reference for the three newer analyzers.

The data were collected at $10 \mathrm{~Hz}$ and processed using EddyUH software in $30 \mathrm{~min}$ increments, primarily following the methodology described by Aubinet et al. (2000). Spectral and co-spectral analyses were conducted using Fast Fourier Transform applied to a linearly detrended raw highfrequency data. Cospectra were used to determine frequency response of the measurement systems. Statistical analyses were conducted to evaluate random and systematic error in tested measurements.

All four gas analyzers performed quite well, and have proven suitable for eddy covariance measurements of methane flux at the study site. The observed differences were due to multiple factors, including instrument performance, instrument design (e.g., open-path vs. closed-path, different laser technologies), stage of instrument development (e.g., production unit vs. early prototype), experimental setup (e.g., closer to vs. further away from the ground; different intake lengths and flow rates), data processing (e.g., internal water vapor correction vs external WPL terms), and available data coverage (e.g, full season with high and low fluxes, part of mid-season with high fluxes, early-season with low fluxes).

Overall, in terms of flux magnitudes, none of the four tested analyzers have shown statistically significant diurnal variation for the methane fluxes and fluxes obtained with the four instruments were not significantly different from each other. In terms of field performance, the RMT-200 was the overall best performer, making it a recommended choice in grid-powered sites, while the Prototype-7700 is lightweight and low-power instrument, making it a practical choice for measurement sites in remote locations.

Acknowledgements. We would like to thank LI-COR Biosciences for lending the early prototype of the LI-7700 instrument. For funding we thank Magnus Ehrnrooth foundation, the Academy of Finland Centre of Excellence program (project no. 1118615), the Academy of Finland ICOS project (263149), Nordfrosk project DEFROST, EU projects ICOS, GHG-Europe and InGOS.

Edited by: X. Wang

\section{References}

Aubinet, M., Grelle, A., Ibrom, A., Rannik, U., Moncrieff, J., Foken, T., Kowalski, A. S., Martin, P. H., Berbigier, P., Bernhofer, C., Clement, R., Elbers, J., Granier, A., Grunwald, T., Morgenstern, K., Pilegaard, K., Rebmann, C., Snijders, W., Valentini, R., and Vesala, T.: Estimates of the annual net carbon and water exchange of forests: The EUROFLUX methodology, Adv. Ecol. Res., 30, 113-175, 2000.
Aurela, M., Riutta, T., Laurila, T., Tuovinen, J. P., Vesala, T., Tuittila, E. S., Rinne, J., Haapanala, S., and Laine, J.: $\mathrm{CO}_{2}$ exchange of a sedge fen in southern Finland - The impact of a drought period, Tellus Series B, 59, 826-837, 2007.

Baer, D. S., Paul, J. B., Gupta, J. B., and O'Keefe, A.: Sensitive absorption measurements in the near-infrared region using off-axis integrated-cavity-output spectroscopy, Appl. Phys. B, 75, 261265, 2002.

Billesbach, D., Kim, J., Clement, R., Verma, S., and Ullman, F.: An intercomparison of two tunable diode laser spectrometers used for eddy correlation measurements of methane flux in a prairie wetland, J. Atmos. Oc. Technol., 15, 197-206, 1998.

Billesbach, D. P.: Estimating uncertainties in individual eddy covariance flux measurements: A comparison of methods and a proposed new method, Agr. Forest Meteorol., 151, 394-405, 2011.

Burba, G., McDermitt, D., Komissarov, A., Anderson, T., Xu, L., and Riensche, B.: Method and apparatus for determining gas flux, US Patent 7953558: Filed September 3, 2009; Granted May 31, 2011. International Patent PCT/US2009/055936: Filed September 3, 2009; Granted 1 January 2010, 2009.

Burba, G., Schmidt, A., Scott, R. L., Nakai, T., Kathilankal, J., Fratini, G., Hanson, C., Law, B., McDermitt, D. K., Eckles, R., Furtaw, M., and Velgersdyk, M.: Calculating $\mathrm{CO}_{2}$ and $\mathrm{H}_{2} \mathrm{O}$ eddy covariance fluxes from an enclosed gas analyzer using an instantaneous mixing ratio, Global Change Biol., 18, 385-399, 2012.

Burch, D. E., Singleton, E. B., and Williams, D.: Absorption Line Broadening in the Infrared, Appl. Optics, 1, 359-363, 1962.

Businger, J. A.: Evaluation of the Accuracy with which Dry Deposition can be Measured with Current Micrometeorological Techniques, J. Clim. Appl. Meteorol., 25, 1100-1124, 1986.

Chen, H., Winderlich, J., Gerbig, C., Hoefer, A., Rella, C. W., Crosson, E. R., Pelt, A. D. V., Steinbach, J., Kolle, O., Beck, V., Daube, B. C., Gottlieb, E. W., Chow, V. Y., Santoni, G. W., and Wofsy, S. C.: High-accuracy continuous airborne measurements of greenhouse gases $\left(\mathrm{CO}_{2}\right.$ and $\left.\mathrm{CH}_{4}\right)$ using the cavity ring-down spectroscopy (CRDS) technique, Atmos. Measurem. Techn., 3, 375-386, 2010.

Conrad, R.: Control of Methane Production in Terrestrial Ecosystems, vol. 47, John Wiley \& Sons Ltd, Chichester, 1989.

Dengel, S., Levy, P. E., Grace, J., Jones, S. K., and Skiba, U. M.: Methane emissions from sheep pasture, measured with an openpath eddy covariance system, Global Change Biol., 17, 35243533, 2011.

Detto, M., Verfaillie, J., Anderson, F., Xu, L., and Baldocchi, D.: Comparing laser-based open- and closed-path gas analyzers to measure methane fluxes using the eddy covariance method, Agr. Forest Meteoro., 151, 1312-1324, 2011.

Drebs, A., Nordlund, A., Karlsson, P., Helminen, J., and Rissanen, P.: Climatological statistics of Finland 1971-2000, Finnish Meteorological Institute, Helsinki, 2002.

Eugster, W. and Pluess, P.: A fault-tolerant eddy covariance system for measuring $\mathrm{CH}(4)$ fluxes, Agr. Forest Meteorol., 150, 841851, 2010.

Finkelstein, P. and Sims, P.: Sampling error in eddy correlation flux measurements, J. Geophys. Res.-Atmos., 106, 3503-3509, 2001.

Foken, T. and Wichura, B.: Tools for quality assessment of surfacebased flux measurements, Agr. Forest Meteorol., 78, 83-105, 1996. 
Goulden, M. L., Munger, J. W., Fan, S. M., Daube, B. C., and Wofsy, S. C.: Measurements of carbon sequestration by long-term eddy covariance: Methods and a critical evaluation of accuracy, Global Change Biol., 2, 169-182, 1996.

Hendriks, D. M. D., Dolman, A. J., van der Molen, M. K., and van Huissteden, J.: A compact and stable eddy covariance set-up for methane measurements using off-axis integrated cavity output spectroscopy, Atmos. Chem. Phys., 8, 431-443, doi:10.5194/acp-8-431-2008, 2008.

Horst, T. W.: A simple formula for attenuation of eddy fluxes measured with first-order-response scalar sensors, Bound.-Lay. Meteorol., 82, 219-233, 1997.

Ibrom, A., Dellwik, E., Larsen, S. E., and Pilegaard, K.: On the use of the Webb-Pearman-Leuning theory for closed-path eddy correlation measurements, Tellus Series B, 59, 937-946, 2007.

Kaimal, J. C. and Finnigan, J. J.: Atmospheric boundary layer flows : their structure and measurement, Oxford University Press, New York, 1994.

Kaimal, J. C., Wyngaard, J. C., Izumi, Y., and Cotè, O. R.: Spectral characteristics of surface-layer turbulence., Quart. J. Roy. Meteorol. Soc., 98, 563-589, 1972.

Kroon, P. S., Schrier-Uijl, A. P., Hensen, A., Veenendaal, E. M., and Jonker, H. J. J.: Annual balances of $\mathrm{CH}_{4}$ and $\mathrm{N}_{2} \mathrm{O}$ from a managed fen meadow using eddy covariance flux measurements, Euro. J. Soil Sci., 61, 773-784, 2010.

Lee, X. and Massman, W. J.: A Perspective on Thirty Years of the Webb, Pearman and Leuning Density Corrections, Bound.-Lay. Meteorol., 139, 37-59, 2011.

Leuning, R. and Moncrieff, J.: Eddy-Covariance $\mathrm{CO}_{2}$ Flux Measurements using Open-Path and Closed-Path $\mathrm{CO}_{2}$ Analyzers Corrections for Analyzer Water-Vapor Sensitivity and Damping of Fluctuations in Air Sampling Tubes, Bound.-Lay. Meteorol., 53, 63-76, 1990.

Mammarella, I., Werle, P., Pihlatie, M., Eugster, W., Haapanala, S., Kiese, R., Markkanen, T., Rannik, Ü., and Vesala, T.: A case study of eddy covariance flux of $\mathrm{N} 2 \mathrm{O}$ measured within forest ecosystems: quality control and flux error analysis, Biogeosciences, 7, 427-440, doi:10.5194/bg-7-427-2010, 2010.

Massman, W. J. and Tuovinen, J. P.: An analysis and implications of alternative methods of deriving the density (WPL) terms for eddy covariance flux measurements, Bound.-Lay. Meteorol., 121, 221-227, 2006.

McBean, G. A. and Elliott, J. A.: Vertical Transports of KineticEnergy by Turbulence and Pressure in Boundary-Layer, J. Atmos. Sci., 32, 753-766, 1975.

McDermitt, D., Burba, G., Xu, L., Anderson, T., Komissarov, A., Riensche, B., Schedlbauer, J., Starr, G., Zona, D., Oechel, W., Oberbauer, S., and Hastings, S.: A new low-power, open-path instrument for measuring methane flux by eddy covariance, Appl. Phys. B, 102, 391-405, 2010.
Nakai, T., Iwata, H., and Harazono, Y.: Importance of mixing ratio for a long-term $\mathrm{CO}_{2}$ flux measurement with a closed-path system, Tellus Series B, 63, 302-308, 2011.

Neftel, A., Ammann, C., Fischer, C., Spirig, C., Conen, F., Emmenegger, L., Tuzson, B., and Wahlen, S.: $\mathrm{N}_{2} \mathrm{O}$ exchange over managed grassland: Application of a quantum cascade laser spectrometer for micrometeorological flux measurements, Agr. Forest Meteorol., 150, 775-785, 2010.

O'Keefe, A. and Deacon, D. A. G.: Cavity Ring-Down Optical Spectrometer for Absorption-Measurements using Pulsed Laser Sources, Rev. Sci. Instr., 59, 2544-2551, 1988.

Rannik, U. and Vesala, T.: Autoregressive filtering versus linear detrending in estimation of fluxes by the eddy covariance method, Bound.-Lay. Meteorol., 91, 259-280, 1999.

Rannik, U., Vesala, T., and Keskinen, R.: On the damping of temperature fluctuations in a circular tube relevant to the eddy covariance measurement technique, J. Geophys. Res.-Atmos., 102, 12789-12794, 1997.

Rinne, J., Riutta, T., Pihlatie, M., Aurela, M., Haapanala, S., Tuovinen, J. P., Tuittila, E. S., and Vesala, T.: Annual cycle of methane emission from a boreal fen measured by the eddy covariance technique, Tellus B, 59, 449-457, 2007.

Riutta, T., Laine, J., Aurela, M., Rinne, J., Vesala, T., Laurila, T., Haapanala, S., Pihlatie, M., and Tuittila, E. S.: Spatial variation in plant community functions regulates carbon gas dynamics in a boreal fen ecosystem, Tellus Series B, 59, 838-852, 2007.

Schotanus, P., Nieuwstadt, F. T. M., and Debruin, H. A. R.: Temperature-Measurement with a Sonic Anemometer and its Application to Heat and Moisture Fluxes, Bound.-Lay. Meteorol., 26, 81-93, 1983.

Stull, R. B.: An Introduction to Boundary Layer Meteorology, Kluwer Academic Publishers, The Netherlands, 1 Edn., 1988.

Suyker, A., Verma, S., Clement, R., and Billesbach, D.: Methane flux in a boreal fen: Season-long measurement by eddy correlation, J. Geophys. Res.-Atmos., 101, 28637-28647, 1996.

Tuzson, B., Hiller, R. V., Zeyer, K., Eugster, W., Neftel, A., Ammann, C., and Emmenegger, L.: Field intercomparison of two optical analyzers for $\mathrm{CH}_{4}$ eddy covariance flux measurements, Atmos. Measurem. Techn., 3, 1519-1531, 2010.

Verma, S. B., Ullman, F. G., Billesbach, D. P., Clement, R. J., Kim, J., and Verry, E. S.: Eddy-Correlation Measurements of Methane Flux in a Northern Peatland Ecosystem, Bound.-Lay. Meteorol., 58, 289-304, 1992.

Webb, E. K., Pearman, G. I., and Leuning, R.: Correction of Flux Measurements for Density Effects due to Heat and Water-Vapor Transfer, Quart. J. Roy. Meteorol. Soc., 106, 85-100, 1980.

Zhang, J., Lee, X., Song, G., and Han, S.: Pressure correction to the long-term measurement of carbon dioxide flux, Agr. Forest Meteorol., 151, 70-77, 2011. 